

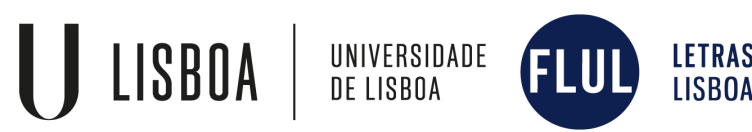

OPHIUSSA. Revista do Centro de Arqueologia da Universidade de Lisboa

ISSN 1645-653X / E-ISSN 2184-173X

Publicação anual

Volume $2-2018$

Direcção e Coordenação Editorial:

Ana Catarina Sousa

Elisa Sousa

Conselho Científico:

André Teixeira (Universidade Nova de Lisboa)

Carlos Fabião (Universidade de Lisboa)

Catarina Viegas (Universidade de Lisboa)

Gloria Mora (Universidad Autónoma de Madrid)

Grégor Marchand (Centre National de la Recherche Scientifique)

João Pedro Bernardes (Universidade do Algarve)

José Remesal (Universidade de Barcelona)

Leonor Rocha (Universidade de Évora)

Manuela Martins (Universidade do Minho)

Maria Barroso Gonçalves (Instituto Superior de Ciências do Trabalho e da Empresa)

Mariana Diniz (Universidade de Lisboa)

Raquel Vilaça (Universidade de Coimbra)

Xavier Terradas Battle (Consejo Superior de Investigaciones Científicas)

Secretariado: André Pereira

Capa: André Pereira sobre vaso cerâmico de Camposoto (desenho de António Sáez Romero / Joan Ramon Torres).

Paginação: Elisa Sousa

Impressão: Europress

Data de impressão: Dezembro de 2018

Edição impressa (preto e branco): 300 exemplares

Edição digital (a cores): www.ophiussa.letras.ulisboa.pt

ISSN: 1645-653X / E-ISSN 2184-173X

Depósito legal: 190404/03

Copyright @ 2018 , os autores

Edição:

UNIARQ - Centro de Arqueologia da Universidade de Lisboa, Faculdade de Letras de Lisboa, 1600-214 - Lisboa.

www.uniarq.net - www.ophiussa.letras.ulisboa.pt - uniarq@letras.ulisboa.pt

Revista fundada por Victor S. Gonçalves (1996).

O cumprimento do acordo ortográfico de 1990 foi opção de cada autor.

Esta publicação é financiada por fundos nacionais através da FCT - Fundação para a Ciência e a Tecnologia, I.P., no âmbito do projecto UID/ARQ/00698/2013. 


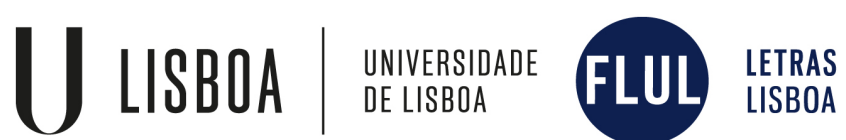

\section{A TECNOLOGIA LÍTICA DO FIM DO TARDIGLACIAR NO CENTRO DE PORTUGAL: O EXEMPLO DO ABRIGO 1 DE VALE DE COVÕES (SOURE)}

\author{
LITHIC TECHNOLOGY DURING THE TARDIGLACIAL \\ IN CENTRAL PORTUGAL: THE EXAMPLE OF \\ ABRIGO 1 DE VALE DE COVÕES (SOURE)
}

CRISTINA GAMEIRO'

\section{RESUMO}

O Abrigo 1 de Vale de Covões foi identificado, por T. Aubry, em 2001, e nesse mesmo ano, no âmbito de um projecto alargado sobre a ocupação pré-histórica do Maciço de Sicó, foi empreendida uma sondagem de $1 \mathrm{~m}^{2}$ para averiguação da potência estratigráfica. A identificação de níveis preliminarmente atribuídos ao Magdalenense e ao Gravettense motivou uma campanha de escavação em 2004. Neste artigo apresentamos a descrição e a nossa interpretação sobre a tecnologia dos artefactos líticos recuperados nas unidades estratigráficas 3 e 4 deste abrigo. Um carvão recolhido na unidade estratigráfica 4 possibilitou a obtenção de uma data de 10 020 40 BP (Cal 9769-9367 BC), convergente com a atribuição crono-cultural ao Magdalenense Final. O estudo da indústria lítica das unidades estratigráficas que aqui apresentamos foi levado a cabo no âmbito de um trabalho académico e os estudos faunísticos, geo-arqueológicos e datações para a totalidade da sequência estão ainda em curso.

Palavras-chave: Paleolítico Superior; Magdalenense; Tardiglaciar; Tecnologia Lítica; Aprovisionamento matérias-primas.

\begin{abstract}
The rock shelter 1 of Vale de Covões was identified, by T. Aubry, in 2001, and in that same year, to assess the stratigraphy, a $1 \mathrm{~m}^{2}$ test pit was carried out as part of an extensive project on the prehistoric occupation of the Sicó Massif. The identification of levels preliminarily attributed to the Magdalenian and to the Gravettian, motivated an 8m2 excavation in 2004. Whitten this article we present the description and our interpretation on the technology of the lithic artefacts recovered in the stratigraphic units 3 and 4 of this rock shelter. A charcoal collected in the stratigraphic unit 4 allowed to obtain a date of $10020 \pm 40$ BP (Cal 9769-9367 BC) in convergence with the chrono-cultural attribution to the Late Magdalenian. These studies, on the lithic industry, were carried out in the framework of an academic work. The faunal analysis, geo-archaeological studies and dating, for the complete sequence, are still undergoing.
\end{abstract}

Keywords: Upper Paleolithic; Magdalenian; Tardiglacial; Lithic technology; Raw material sourcing. 


\section{INTRODUÇÃO}

O extremo norte da Estremadura, área correspondente à bacia do Mondego, constitui um território com ocupação do Paleolítico Superior documentada (Aubry - Moura 1993; Aubry - Fontugne - Moura 1997; Aubry et al. 1998; Aubry et al. 2001; Aubry - Dimuccio - Moura 2017). Contudo, a escassez de dados e a inexistência de longas sequências sedimentares bem preservadas, faz com que a identificação recente de um Abrigo com ocupação durante o Paleolítico Superior possa aportar dados que melhorem o nosso conhecimento sobre o povoamento, tecnologia e subsistência nesta região. O nosso conhecimento sobre a transição PlistocénicoHolocénico é ainda elementar, apesar de, nos últimos anos, termos assistido à identificação de novos sítios com ocupação humana durante o Alleröd e o Dryas III, e, consequentemente, ter aumentando o nosso conhecimento sobre o Tardiglaciar (Andrade - Matias - Mântua 2010-2011; Gameiro - Aubry - Almeida 2013; Gameiro - Davis - Almeida 2017; Aubry et al. 2017).

Neste artigo apresentaremos dados relativos à indústria lítica recuperada nas unidades estratigráficas 3 e 4, ou seja os níveis correspondentes ao topo da sequência sedimentar identificada no Abrigo 1 de Vale de Covões. Estes vestígios corresponderam a ocupações humanas no local, provavelmente, durante o final do Alleröd ou início do Dryas III. Procuramos compreender a organização económica, a tecnologia e avançar alguns dados sobre a mobilidade dos grupos humanos no centro de Portugal durante o Tardiglaciar.
O estudo da indústria lítica destas unidades estratigráficas foi levado a cabo no âmbito de um trabalho académico (Gameiro 2012), o estudo da indústria lítica da unidade estratigráfica 5 foi já sumariamente publicado (Aubry - Zilhão - Almeida 2007; Klaric - Guellermin - Aubry 2010) e os estudos faunísticos e geo-arqueológicos sobre a totalidade da sequência estão em curso. A aparente contradição entre as datações de radiocarbono obtidas e as atribuições culturais tipo-tecnológicas (Aubry et al. 2008; Klaric - Guellermin - Aubry 2010) para a base da sequência (unidades estratigráficas 5 a 8) motivaram a realização de datações por OSL, cujos resultados continuam por apurar, facto que tem justificado o atraso na publicação dos resultados já obtidos para este sítio. Relativamente às unidades estratigráficas 3 e 4, e até à data, apenas foram publicados dados sobre o aprovisionamento das matérias-primas (Gameiro - Aubry - Almeida 2008; Aubry et al. 2016), sobre a traceologia (Aubry - Igreja 2008) e sobre o tipo de percutor utilizado na debitagem lamelar (Gameiro 2017).

\section{APRESENTAÇÃO DO SÍTIO}

Do ponto de vista administrativo o Abrigo 1 de Vale de Covões situa-se na Freguesia de Tapéus, concelho de Soure, Distrito de Coimbra. O Vale dos Covões localiza-se a cerca de $300 \mathrm{~m}$ de altitude, no bordo ocidental do Maciço de Sicó, desenvolvendo-se numa falha perpendicular à falha do Vale das Buracas, numa área onde o substrato calcário do Jurássico médio é afectado pelo modelamento cársico (Fig.

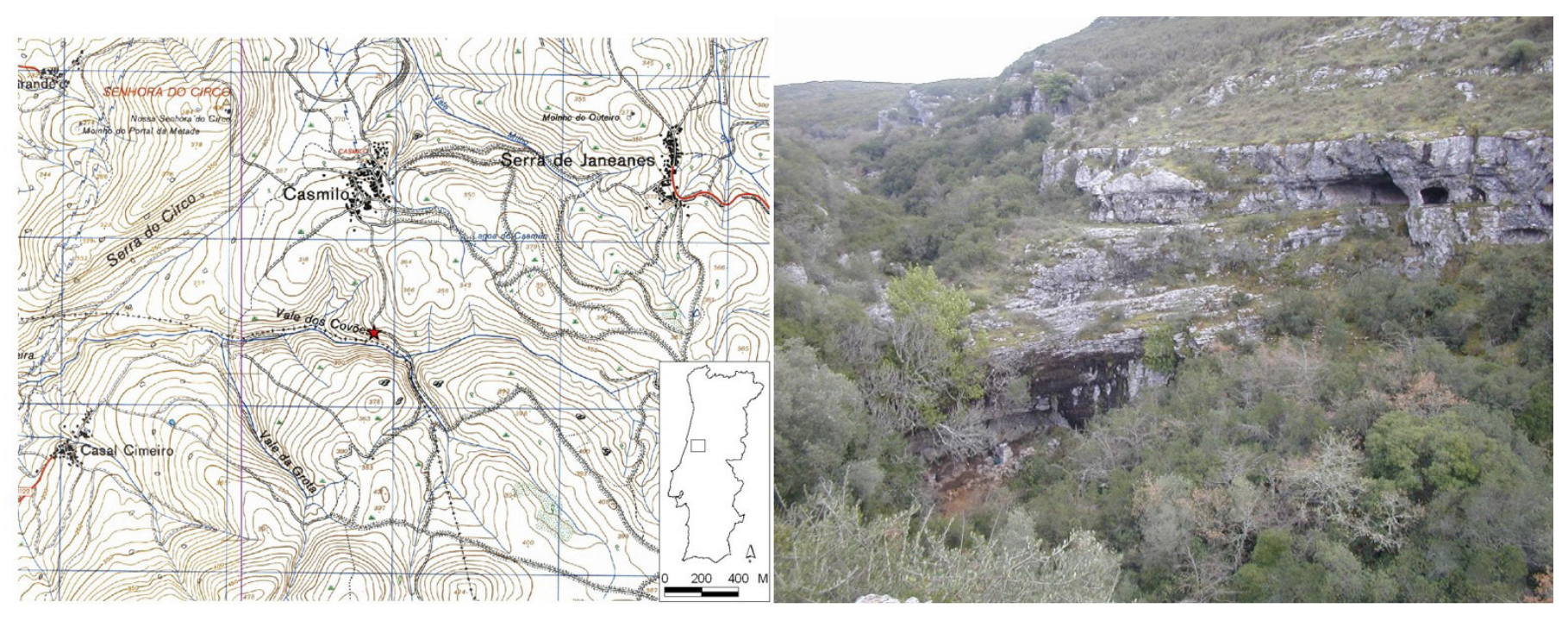

Fig. 1 - Localização do Abrigo 1 de Vale de Covões nas folhas 250 e 251 da Carta Militar de Portugal (1/25 000cm) e vista panorâmica geral do Vale de Covões. Foto de T. Aubry. 
1). O Vale das Buracas corresponde a um canhão fluvio-cársico de vertente escarpada e as Buracas correspondem à denominação local para pequenos abrigos sobre rocha, resultantes de processos de gelifracção diferencial e de dissolução da parede rochosa durante um clima frio (Cunha 1986).

A localização deste pequeno abrigo, junto a uma exsurgência sazonal e próximo de fontes de sílex apresenta condições naturais que, certamente, favoreceram a implantação humana neste local.

\section{METODOLOGIA}

\subsection{ESCAVAÇÃO}

O sítio foi identificado por T. Aubry em 2001 e nesse mesmo ano, no âmbito de um projecto alargado sobre a ocupação pré-histórica do Maciço de Sicó, foi empreendida uma sondagem de $1 \mathrm{~m}^{2}$ para averiguação da potência estratigráfica. A identificação de níveis preliminarmente atribuídos ao Magdalenense e ao Gravettense motivou uma campanha de escavação em 2004 (Fig. 2). Em torno da sondagem inicial foi aberta uma área de $8 \mathrm{~m}^{2}$. A escavação foi efectuada por decapagens de $5 \mathrm{~cm}$ e de acordo com as unidades estratigráficas identificadas. Todas as peças identificadas durante a escavação foram coordenadas tridimensionalmente. Todos os sedimentos foram crivados a água, tendo sido utilizado um crivo com malha de $2 \mathrm{~mm}$.

\subsection{ESTRATIGRAFIA}

A sequência estratigráfica (Fig. 3) identificada desenvolve-se sobre cerca de $2 \mathrm{~m}$ de potência e foi já publicada (Aubry et al. 2008). Um total de 11 unidades estratigráficas foram identificadas e estas podem ser reagrupadas em 4 conjuntos sedimentares, separados por 4 discontinuidades (Aubry et al. 2008; Aubry et al. 2010). As fases erosivas reconhecidas são comparáveis com outras identificadas em sequências englobando ocupações Gravettenses no Maciço de Sicó (Aubry et al. 2008; Aubry et al. 2010), facto que parece concordar com a observação tecnológica da indústria lítica (Aubry - Igreja 2008; Klaric - Guillermin - Aubry 2010).

\subsection{DATAÇÃO}

Foram realizadas oito datações de radiocarbono para a totalidade da sequência (UE4 a UE8b). De momento, as datações de radiocarbono existentes

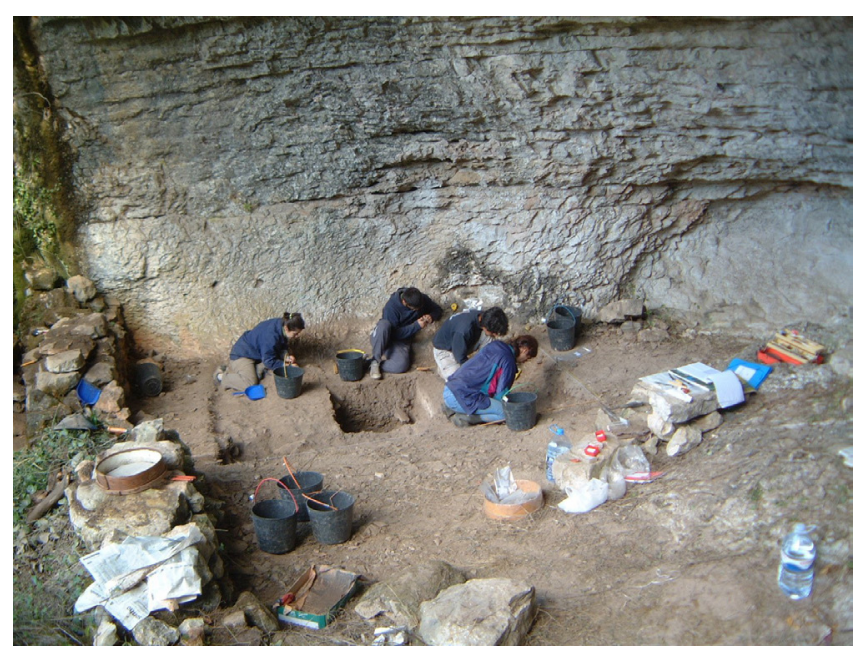

Fig. 2 - Aspecto dos trabalhos de escavação em 2004. Foto de T. Aubry.

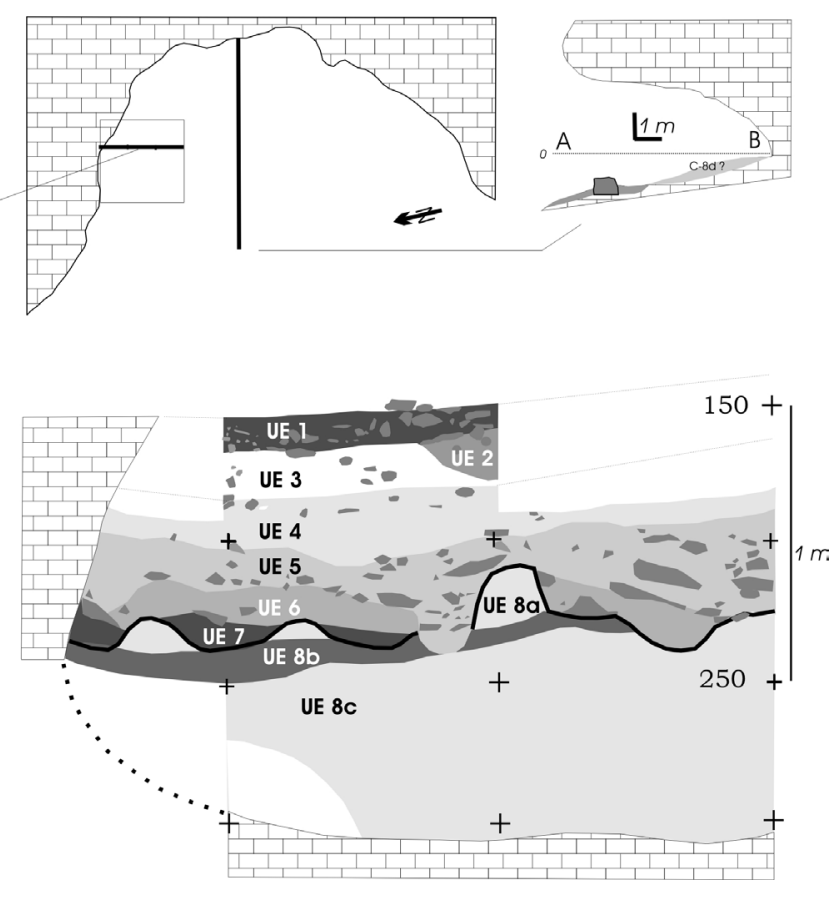

Fig. 3 - Planta geral do Abrigo e corte Este. Desenho de M. Almeida e T. Aubry.

situam-se entre os 12700 e os 9100 Cal BC (Fig. 4). Um carvão recolhido na unidade estratigráfica 4 possibilitou a obtenção de uma data de $10020 \pm 40$ BP (Cal 9769-9367 BC). Contudo, para as unidades 5-8b é notória uma incoerência, entre os resultados e a comparação tecno-tipológica da indústria lítica, que tem sido justificada por um rejuvenescimento do material em osso, resultante de contaminação por ácidos húmicos, e, para os carvões datados na base da sequência, uma percolação a partir dos níveis superiores. Este duplo fenómeno pode ser explicado 


\begin{tabular}{|c|c|c|c|c|c|c|}
\hline Sítio & Camada & $\begin{array}{c}\text { Ref. } \\
\text { Laboratório }\end{array}$ & Amostra & Data BP & Data Cal BC $(2 \sigma)$ * & Publicação \\
\hline $\begin{array}{l}\text { Abrigo } 1 \text { Vale de } \\
\text { Covões }\end{array}$ & 4 & Beta-201014 & Carvão & $10020 \pm 40$ & $9769-9367$ & Aubry et al. 2008 \\
\hline $\begin{array}{l}\text { Abrigo } 1 \text { Vale de } \\
\text { Covões }\end{array}$ & 5 & Beta-201013 & Osso & $12340 \pm 50$ & $12737-12153$ & Aubry et al. 2008 \\
\hline $\begin{array}{l}\text { Abrigo } 1 \text { Vale de } \\
\text { Covões }\end{array}$ & 5 & UA33479 & Osso & $10540 \pm 95$ & $10746-10191$ & $\begin{array}{l}\text { Klaric - Guillermin - Aubry } \\
2009\end{array}$ \\
\hline $\begin{array}{l}\text { Abrigo } 1 \text { Vale de } \\
\text { Covões }\end{array}$ & 7 & UA33480 & Osso & $9725 \pm 75$ & $9315-8837$ & $\begin{array}{l}\text { Klaric - Guillermin - Aubry } \\
2009\end{array}$ \\
\hline $\begin{array}{l}\text { Abrigo } 1 \text { Vale de } \\
\text { Covões }\end{array}$ & $8 b$ & UA33481 & Osso & $9315 \pm 90$ & $8775-8305$ & $\begin{array}{l}\text { Klaric - Guillermin - Aubry } \\
2009\end{array}$ \\
\hline $\begin{array}{l}\text { Abrigo } 1 \text { Vale de } \\
\text { Covões }\end{array}$ & $8 b$ & UA24593 & Osso & $10010 \pm 90$ & $9991-9291$ & Aubry et al. 2008 \\
\hline $\begin{array}{l}\text { Abrigo } 1 \text { Vale de } \\
\text { Covões }\end{array}$ & $8 b$ & UA33482 & Carvão & $12050 \pm 70$ & $12129-11782$ & $\begin{array}{l}\text { Klaric - Guillermin - Aubry } \\
2009\end{array}$ \\
\hline $\begin{array}{l}\text { Abrigo } 1 \text { Vale de } \\
\text { Covões }\end{array}$ & $8 b$ & Gif-12080 & Carvão & $12220 \pm 24$ & $12274-12059$ & Aubry et al. 2008 \\
\hline
\end{tabular}

Fig. 4 - Datações de radiocarbono (AMS) do Abrigo 1 de Vale de Covões. *Calibração a $2 \sigma$ segundo OxCal v4.3.2 Bronk Ramsey (2017); r-5; IntCal 13 Atmospheric curve (Reimer et al. 2013).

\begin{tabular}{|c|c|c|c|c|c|c|c|c|c|c|c|}
\hline \multirow{3}{*}{$\begin{array}{l}\text { Tipo de } \\
\text { artefacto }\end{array}$} & \multicolumn{11}{|c|}{ Matéria-prima } \\
\hline & \multicolumn{6}{|c|}{ Sílex e Silcrete } & \multirow[t]{2}{*}{ Quartzo } & \multirow{2}{*}{$\begin{array}{c}\text { Quartzo } \\
\text { Hialino }\end{array}$} & \multirow[t]{2}{*}{ Quartzito } & \multirow[t]{2}{*}{ Outras } & \multirow[t]{2}{*}{ TOTAL } \\
\hline & E1 & C1 & C3 & D2/D3 & F2 & Ind. & & & & & \\
\hline Núcleo & & 2 & 1 & & & & 1 & & & & 4 \\
\hline $\begin{array}{l}\text { Fragmento } \\
\text { de núcleo }\end{array}$ & 1 & & 1 & & & 1 & 2 & 1 & & & 6 \\
\hline Tablettes & 1 & 1 & & & & & & & & & 2 \\
\hline $\begin{array}{l}\text { Lamelas de } \\
\text { crista }\end{array}$ & 1 & 1 & & & & & & & & & 2 \\
\hline $\begin{array}{l}\text { Lascas não } \\
\text { corticais }\end{array}$ & 13 & 122 & 10 & 4 & 2 & & 38 & & 11 & & 200 \\
\hline $\begin{array}{l}\text { Lascas } \\
\text { corticais }\end{array}$ & 4 & 31 & 3 & 2 & 1 & & 15 & & 11 & & 67 \\
\hline $\begin{array}{l}\text { Fragmento } \\
\text { de lasca }\end{array}$ & 8 & 64 & 6 & 4 & 1 & & 31 & & 9 & & 123 \\
\hline Lâminas & 1 & 4 & & & & & & & & & 5 \\
\hline Lamelas & 13 & 20 & 5 & 1 & & & 2 & & & 2 & 43 \\
\hline $\begin{array}{l}\text { Lamelas de } \\
\text { buril }\end{array}$ & 4 & 3 & & 1 & & & & & & & 8 \\
\hline $\begin{array}{l}\text { Lamelas } \\
\text { corticais }\end{array}$ & 3 & 2 & & & & & & & & & 5 \\
\hline Utensílios & 19 & 13 & & 1 & & & 11 & & 1 & & 45 \\
\hline $\begin{array}{l}\text { Termoclas- } \\
\text { tos }\end{array}$ & 12 & 119 & & 1 & & & 11 & & & & 143 \\
\hline Fragmentos & 1 & 3 & 1 & & 1 & & 1 & & & & 7 \\
\hline Esquírolas & 37 & 142 & 7 & & 1 & & 115 & & 9 & 1 & 312 \\
\hline \multirow[t]{2}{*}{ TOTAL } & 117 & 526 & 34 & 14 & 6 & 1 & \multirow{2}{*}{227} & \multirow[b]{2}{*}{1} & \multirow[b]{2}{*}{41} & \multirow[b]{2}{*}{3} & \multirow[b]{2}{*}{970} \\
\hline & & & & & & & & & & & \\
\hline
\end{tabular}

Fig. 5 - Inventário geral, por matéria-prima e classe tecnológica, da totalidade dos materiais líticos recolhidos na UE3. Tipos de sílex: E1/E2 (Cenomaniano); C1 (limite entre Bajociano e Batoniano local); C3 (limite entre Bajociano e Batoniano alóctone); D2/D3 (Oxfordiano); F2 (silcrete Facho); Ind. (indeterminado). 


\begin{tabular}{|c|c|c|c|c|c|c|c|c|c|c|c|c|c|}
\hline \multirow{3}{*}{$\begin{array}{l}\text { Tipo de } \\
\text { artefacto }\end{array}$} & \multicolumn{13}{|c|}{ Matéria-prima } \\
\hline & \multicolumn{8}{|c|}{ Sílex e Silcrete } & \multirow[t]{2}{*}{ Quartzo } & \multirow{2}{*}{$\begin{array}{l}\text { Quartzo } \\
\text { Hialino }\end{array}$} & \multirow[t]{2}{*}{ Quartzito } & \multirow[t]{2}{*}{ Outras } & \multirow[t]{2}{*}{ TOTAL } \\
\hline & E1 & E2 & C1 & C3 & D2/D3 & F2 & SI & Ind. & & & & & \\
\hline Núcleo & & & 6 & & & & 1 & & 4 & & & & 11 \\
\hline $\begin{array}{l}\text { Fragmento } \\
\text { de núcleo }\end{array}$ & 4 & & & 1 & & & & & & & & & 5 \\
\hline $\begin{array}{l}\text { Lascas não } \\
\text { corticais }\end{array}$ & 36 & 2 & 176 & 5 & 3 & 3 & & & 36 & 1 & 18 & 1 & 281 \\
\hline $\begin{array}{l}\text { Lascas } \\
\text { corticais }\end{array}$ & 15 & & 40 & 11 & 4 & & & & 30 & & 21 & & 121 \\
\hline $\begin{array}{l}\text { Fragmento } \\
\text { de lasca }\end{array}$ & 15 & & 83 & 11 & 6 & 1 & & & 74 & & 42 & & 232 \\
\hline Lamelas & 24 & & 35 & 6 & 9 & & & & 2 & 1 & & 1 & 78 \\
\hline $\begin{array}{l}\text { Lamelas de } \\
\text { buril }\end{array}$ & 3 & & 2 & & & & & & & & & & 5 \\
\hline $\begin{array}{l}\text { Lamelas } \\
\text { corticais }\end{array}$ & 1 & & 1 & 1 & & & & & & & & & 3 \\
\hline Utensílios & 33 & & 35 & & 6 & & & 3 & 17 & 1 & 1 & & 96 \\
\hline $\begin{array}{l}\text { Termoclas- } \\
\text { tos }\end{array}$ & 17 & & 234 & 2 & 4 & & & & 14 & & 5 & & 276 \\
\hline Fragmentos & 4 & & 13 & 4 & 1 & & & & 14 & & 2 & 1 & 39 \\
\hline Esquírolas & 142 & & 238 & 16 & 8 & & & & 216 & & 50 & 1 & 671 \\
\hline \multirow[t]{2}{*}{ TOTAL } & 296 & 2 & 867 & 57 & 42 & 4 & 1 & 3 & \multirow{2}{*}{407} & \multirow[b]{2}{*}{3} & \multirow{2}{*}{139} & \multirow[b]{2}{*}{5} & \multirow[b]{2}{*}{1826} \\
\hline & & & & & 72 & & & & & & & & \\
\hline
\end{tabular}

Fig. 6 - Inventário geral, por matéria-prima e classe tecnológica, da totalidade dos materiais líticos recolhidos na UE4. Tipos de sílex: E1 e E2 (Cenomaniano); C1 (limite entre Bajociano e Batoniano local); C3 (limite entre Bajociano e Batoniano alóctone); D2/D3 (Oxfordiano); F2 (silcrete Facho); SI (silcrete indeterminado), Ind. (indeterminado).

pela reactivação de uma exsurgência no fim do Plistocénico ou início do Holocénico e segundo L. Dimuccio, encarregue do estudo geomorfológico, pode ser provado pela existência de uma carbonatação, posterior à formação da sequência (Aubry - Zilhão - Almeida 2007; Aubry et al. 2008). Aguardamos os resultados das datações OSL, no entanto, a datação obtida para a UE4 é considerada coerente com o conteúdo antrópico da mesma.

\subsection{ANÁLISE DE MATERIAIS}

A metodologia utilizada parte do quadro conceptual inerente à abordagem tecnológica de uma colecção lítica (Tixier et al. 1980; Inizan et al. 1995; Pelegrin 1995), utilizando o conceito de cadeia operatória e procurando identificar as fases de aprovisionamento, produção, transformação e abandono de um utensílio. As matérias-primas representadas foram classificadas, de acordo com observações macroscópicas, como locais, regionais ou alóctones seguindo os critérios estabelecidos por Geneste (1992) e segundo a informação disponível sobre a litologia e a geologia regional (Aubry 2009; Gameiro - Aubry - Almeida 2008; Aubry et al. 2016). Para agilizar a comparação entre sítios adoptamos o vocabulário, critérios de análise morfométrica e tipologia de J. Zilhão (1997). A descrição dos núcleos utiliza os conceitos desenvolvidos por N. Pigeot (1987) e adaptados por B. Valentin (1995). A descrição do retoque da utensilagem lamelar remete para os critérios definidos por M. Christensen e B. Valentin (2004).

\section{RESULTADOS}

\subsection{A INDÚSTRIA LIITICA DAS UNIDADES ESTRATIGRÁFICAS 3 E 4}

O conjunto lítico apresentado é pouco numeroso e é composto por um número reduzido de utensílios e núcleos, o que coloca alguma dificuldade 


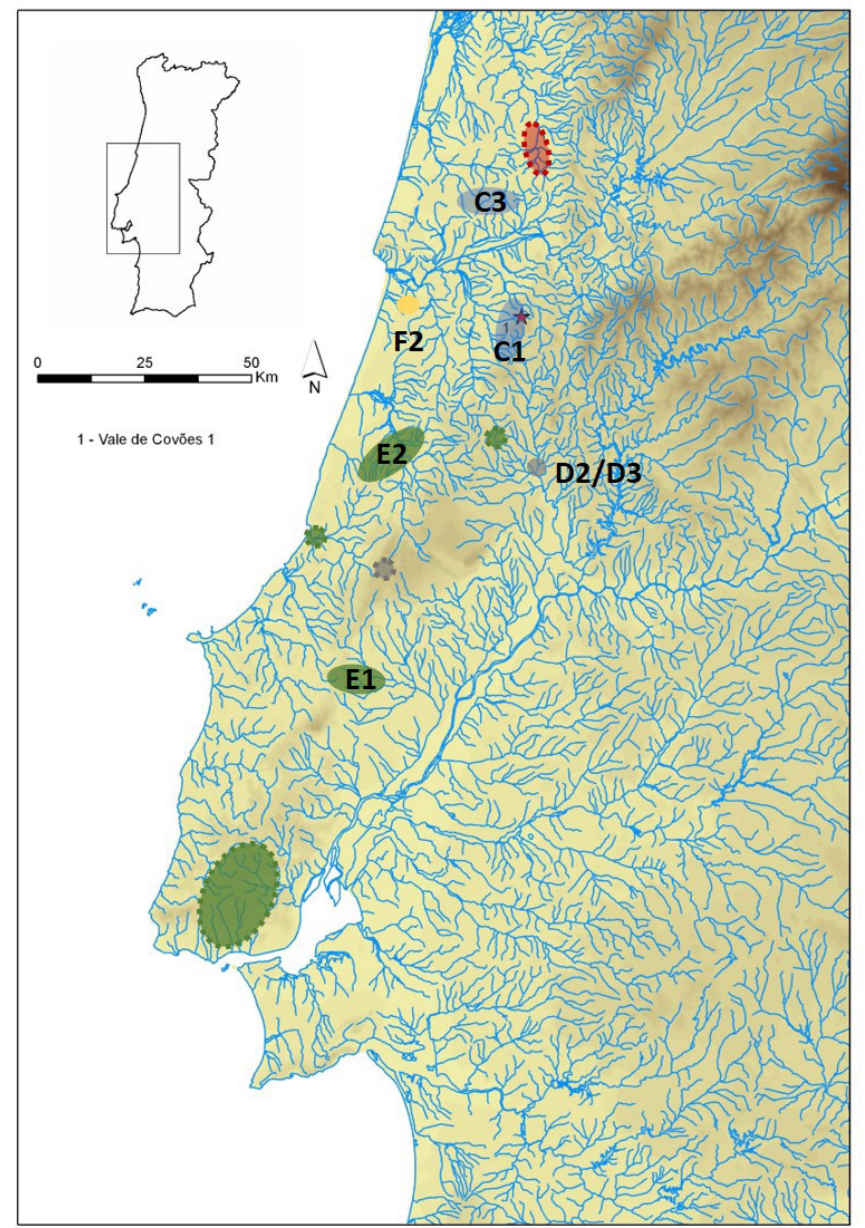

Fig. 7 - Localização do Abrigo 1 de Vale de Covões e das fontes de aprovisionamento em sílex e silcrete utilizadas: E1/E2 (Cenomaniano); C1 (limite entre Bajociano e Batoniano Sicó); C3 (limite entre Bajociano e Batoniano Outil/Ançã); D2/D3 (Oxfordiano do Nabão); F2 (silcrete Facho). Neste mapa representamos com os limites a tracejado algumas fontes de matéria-prima não utilizadas: E4/E5/E6 (respectivamente Cenomaniano de Caxarias, Nazaré e Lisboa) a verde; D5 (Oxfordiano de Moinho da Cabeça) a cinzento e A1 (Hetangiano de Anadia) a vermelho.

na identificação das cadeiras operatórias de produção. A área escavada é igual $\left(9 \mathrm{~m}^{2}\right)$ e, no entanto, na UE4 o número de peças é duas vezes superior. Por prudência, e aguardando os resultados da micromorfologia e de novas datações radiométricas, decidimos apresentar separadamente os dois conjuntos líticos mas é possível que a UE3 constitua o remeximento ou a perturbação do topo da UE 4.

Nas unidades estratigráficas 3 e 4 foram recolhidos, respectivamente, um total de 970 e 1828 artefactos líticos (Fig. 5 e Fig. 6). Este total inclui os termoclastos recuperados: 143 na UE3 e 276 na UE4. A observação dos inventários gerais (Fig. 5 e Fig. 6) permite, de imediato, algumas conclusões: o sílex é a matéria-prima melhor representada $(72 \%$ na UE3 e 69,5\% na UE4) (Fig. 8 e Fig. 9) e a debitagem foi orientada para a produção de lascas e lamelas. A percentagem importante de esquírolas $(44,8 \%$ na UE3 e $36,7 \%$ na UE4) prova a realização de talhe no local (debitagem e retoque) e mostra que não existiu um processo erosivo com potência suficiente para transportar as peças de reduzida dimensão. O elevado número de esquírolas de quartzo, comparativamente com as restantes matérias-primas, pode ser explicado pelas características físicas desta matéria e tal foi já documentado experimentalmente por J-P. Bracco e P. Morel (1998).

\section{As matérias-primas locais $(<5 \mathrm{~km})$}

O trabalho de identificação dos locais de aprovisionamento em sílex, revelou uma exploração maioritária do sílex local proveniente de formações no limite entre Bajociano e Batoniano (C1), disponível em posição primária ou nas formações detríticas situadas a menos de um km do sítio. Trata-se de um sílex com má aptidão ao talhe, seco e de grão grosseiro, nodular e de tamanho variável. Os nódulos de maior dimensão $(10 \mathrm{~cm})$ apresentam grão ainda mais grosseiro. É comum a afectação pela tectónica local originando blocos angulosos e clivagens durante o talhe. As prospecções mostraram que este sílex quando presente em argilas de alteração ou em formações detríticas é afectado por uma epigenia secundária que melhora a aptidão ao talhe (C3). Este tipo de sílex representa $54 \%$ ou $47,5 \%$ do total para a UE3 e UE4, respectivamente. O quartzo e o quartzito estão disponíveis, sob a forma de seixo, nas formações detríticas cretácicas ou terciárias que preenchem as depressões do topo dos afloramentos calcários ou nos depósitos aluviais que ocupam o leito do curso de água sazonal que se sobrepõe ao abrigo. O quartzo constitui $23,4 \%$ do total da indústria lítica presente na UE3 e $22,3 \%$ na UE4. Os artefactos em quartzo comportando vestígios de córtex apresentam sempre um córtex rolado, típico dos seixos e confirmando uma colecta em posição secundária. O quartzito, foi menos explorado e está representado com 4\% para a UE3 e 7,6\% na UE4.

\section{As matérias-primas regionais (5-30km)}

A Norte do Mondego, a cerca de $20 \mathrm{~km}$ do Abrigo, conhecemos sílex no limite entre Bajociano e Batoniano (C3) de melhor aptidão ao talhe do que 
aquele disponível nas imediações do abrigo e esta matéria-prima representa cerca de $5 \%$ do total na UE3 e $4 \%$ do total na UE4. Igualmente em pequena quantidade $(<1 \%)$ foram ainda reconhecidos silcretes, de grão fino, aspecto translúcido, córtex irregular e frequentemente disponível sob a forma de plaquetas e cuja existência se conhece no Facho, na margem esquerda do Mondego, próximo da Figueira da Foz. $\mathrm{Na}$ UE4 foi identificado um núcleo em silcrete (Fig. 20), cuja proveniência não foi possível apurar com exactidão, mas que possivelmente estará disponível nas cascalheiras detríticas pliocénicas da região (a cerca de 10-15km).

\section{As matérias-primas alóctones}

O sílex Cenomaniano (E1/E2), disponível a cerca de $40 \mathrm{~km}$ do abrigo, é a matéria-prima alóctone melhor representada com cerca de $12 \%$ na UE3 e $16,2 \%$ na UE4. Corresponde a um sílex de boa qualidade com grão fino, opaco, de cor variável (do rosa ao amarelo alaranjado). Por vezes, apresenta uma patine, branca ou amarelada, que torna mais difícil a sua identificação. $O$ córtex é, frequentemente, rolado indiciando um aprovisionamento em posição secundária. Como iremos demonstrar, a excelente aptidão ao talhe, desta matéria-prima, fez com que tenha sido seleccionada para a produção de determinadas categorias de utensílios. Em percentagens mais reduzidas (1,7\% para a UE3 e $3 \%$ para a UE4) identificámos sílex Oxfordiano (D2/D3), um sílex de grão fino, opaco de cor acinzentada com córtex primário espesso, disponível a cerca de $30 \mathrm{~km}$ a Sul, no Vale do Nabão.

Não foi possível determinar a proveniência de cerca de $1 \%$ do material em sílex.

\subsubsection{OS MATERIAIS LÍTICOS RECUPERADOS NA UE3}

A indústria lítica foi orientada para a obtenção de lascas e suportes lamelares. Apenas cinco lâminas, em sílex, foram identificadas e destas, duas, apresentam simultaneamente vestígios de córtex e secção triangular, características de uma fase inicial da debitagem. Estes suportes alongados de maiores dimensões não constituem vestígios de uma produção laminar autónoma mas certamente correspondem a uma fase de preparação dos núcleos lamelares. O índice de retoque é baixo e apenas foram identificados 45 utensílios retocados. Destes, 33 são

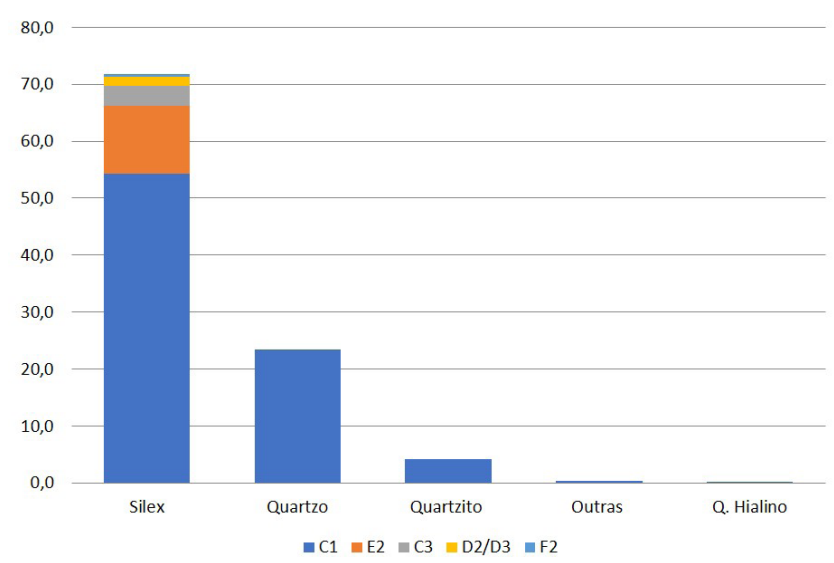

Fig. 8 - Percentagem de utilização das matérias-primas na UE3 do Abrigo 1 de Vale de Covões.

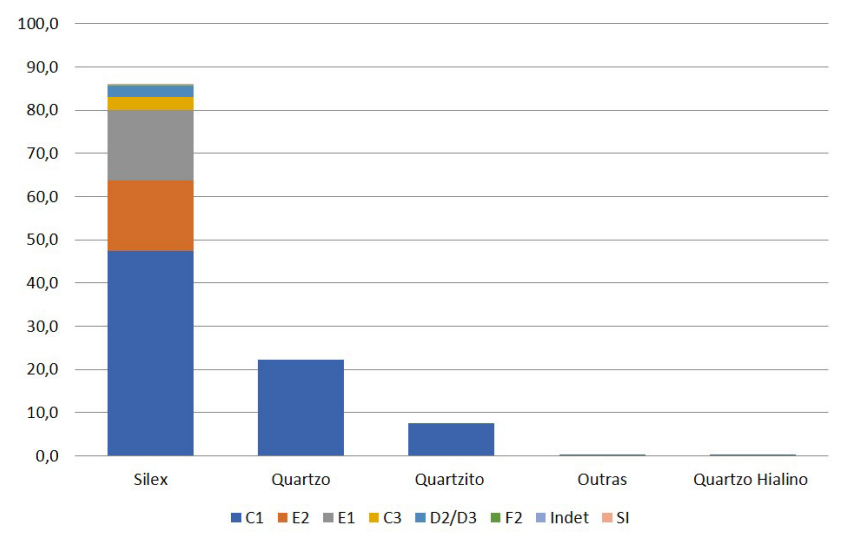

Fig. 9 - Percentagem de utilização das matérias-primas na UE4 do Abrigo 1 de Vale de Covões.

em sílex e os restantes em quartzo (11) e quartzito (1). As lascas constituem a maioria do tipo de suporte retocado $(64,4 \%)$, seguidas pelas lamelas $(31 \%)$ e lâminas (4,4\%).

O talhe claramente foi orientado para a produção de lamelas pequenas, estreitas e finas com dimensões médias entre $15-20 \mathrm{~mm}$ de comprimento, 4-8mm de largura e 1-2mm de espessura (Fig. 10). A análise morfo-tecnológica detalhada das lamelas brutas (28 lamelas e sete lamelas de buril) mostra que a maioria das lamelas tem bordos convergentes (10 exemplares), secção trapezoidal (18 exemplares) e um perfil direito (14 exemplares). A orientação dos negativos anteriores ou padrão dorsal é paralela (10) ou convergente (11) confirmando a tendência para o talhe unidireccional. Grande parte das peças está fragmentada e em apenas 13 exemplares foi possível observar os estigmas relacionáveis com o tipo de percussão: o talão esmagado (seis exemplares), a 


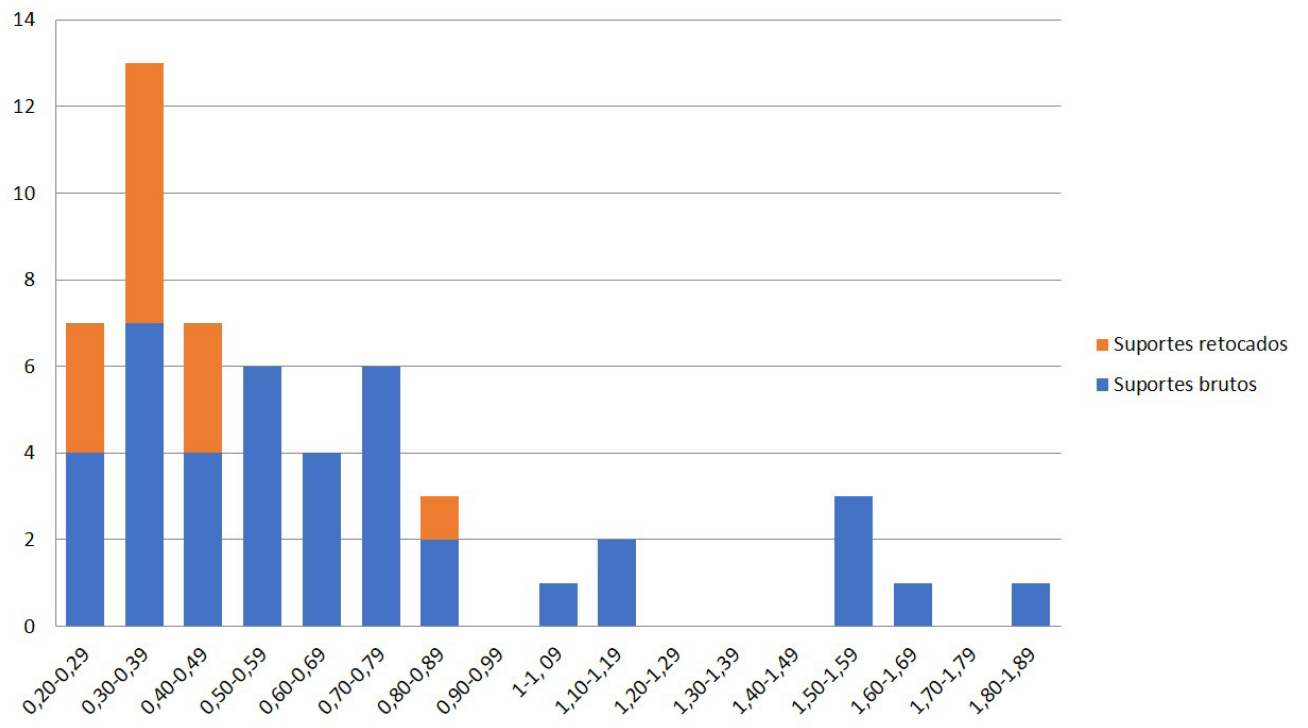

Fig. 10 - Histograma de larguras da totalidade dos suportes alongados da UE3.

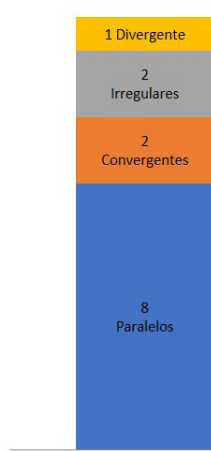

Bordos

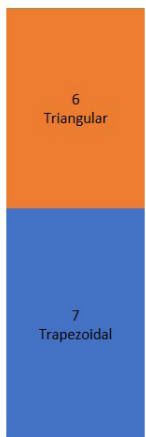

Secção

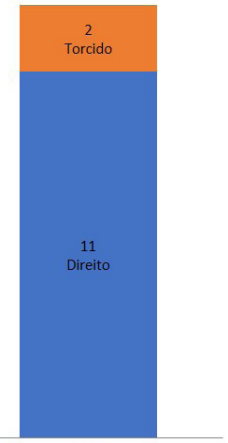

Perfil
Fig. 11 - Morfologia dos bordos, secção e perfil das lamelas retocadas da UE3.

abrasão foi identificada em cinco peças, o labiado em duas, o esquirolamento do bolbo em duas peças e uma linha irregular do talão numa única peça. As lamelas seleccionadas para posterior retoque apresentam as mesmas características morfo-tecnológica (Fig. 11) e distinguem-se apenas pela presença de um número mais significativo de secções triangulares (seis em 13).

Apenas foram recuperados quatro núcleos e seis fragmentos de núcleo, tornando difícil a identificação das cadeias operatórias de debitagem. As suas características detalhadas constam das tabelas apresentadas nas Fig. 18, 19 e 20. Apesar de existirem algumas lamelas em quartzo, nesta

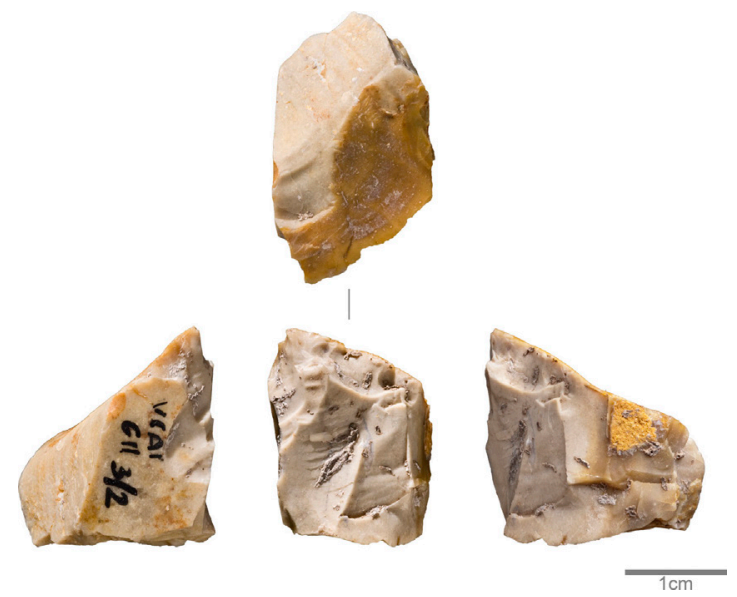

Fig. 12 - Teste sobre um bloco de sílex alóctone do limite entre Bajociano e Batoniano (C3) com vista à debitagem lamelar (UE 3). Foto J. P. Ruas.

matéria-prima apenas recolhemos um núcleo com negativos lamelares e os restantes evidenciam apenas negativos para lascas. Estes núcleos são sobre seixo, a exploração é facial (2) ou bipolar sobre bigorna (1). O eixo de debitagem é sempre inferior a $4 \mathrm{~cm}$ e apesar de algumas clivagens e ressaltos o motivo mais provável para abandono dos núcleos é sempre a sua reduzida dimensão. Em sílex local identificámos um bloco testado (Fig. 12) e um núcleo para lamelas e pequenas lascas (Fig. 13).

Este último é um exemplar de reduzidas dimensões que terá sido, provavelmente, debitado apoiado sobre bigorna, uma vez que evencia algumas marcas típicas desse apoio. Houve algum 
cuidado na preparação deste volume: plano de percussão liso mas sem abrasão, dorso cortical mas com criação de convergência criar uma aresta que tenha possibilitado inicial a debitagem. Os núcleos em sílex Cenomaniano (alóctone) foram explorados intensamente e seguindo estratégias mais elaboradas. A identificação de uma lamela de crista, neste tipo de sílex, demonstra a utilização desta técnica para a preparação dos pequenos volumes explorados com vista à obtenção de lamelas. No entanto, a estratégia mais utilizada consiste na utilização de um diedro natural para inicial a debitagem. A preparação é reduzida e o dorso e os flancos permanecem, frequentemente, corticais. A superfície de debitagem apresenta um formato sub-rectangular e o plano de percussão, sempre liso, apresenta ângulos na ordem dos $70^{\circ}$. A exploração é intensa mas a reduzida dimensão dos volumes faz que com que a produção seja reduzida. A progressão da debitagem é semigiratória, continua, frequentemente, com recuo oblíquo. A debitagem é sempre unidireccional mesmo quando existem dois planos de percussão (utilizados de forma sucessiva). Três fragmentos de núcleos (um em sílex Bajociano alóctone e dois em sílex (enomaniano) evidenciam estigmas relacionáveis com debitagem bipolar sobre bigorna e podem testemunhar uma tentativa de produção de pequenas esquírolas, rentabilizando a matéria-prima quando as dimensões (eixo de debitagem $<15 \mathrm{~mm}$ ) não permitem debitagem lamelar (Fig. 14).

A tipologia é maioritariamente $(44,4 \%)$ constituída por lascas com retoque irregular, descontínuo ou atípico (incluindo os fragmentos de peças retocadas), que podemos juntar, pela semelhança morfológica, à utensilagem de fundo comum (11\%) que inclui três entalhes, um denticulado e uma peça esquirolada (Fig. 15). A análise métrica efectuada sobre as lascas retocadas permitiu constatar que em materiais locais (sílex Bajociano e quartzo) as dimensões são similares $(3 \mathrm{~cm}$ de comprimento $X 2,4 \mathrm{~cm}$ de largura) e são superiores às das lascas de sílex Cenomaniano (alóctone) que, em média, não ultrapassam os $2 \mathrm{~cm}$ de comprimento e largura. As raspadeiras constituem 13,3\% do total da utensilagem retocada. Apresentam sempre dimensões reduzidas e, com excepção de uma raspadeira afocinhada em quartzo e uma raspadeira nucleiforme (Fig. 16:5), dominam os tipos finos (Fig.16:4). As raspadeiras espessas, que acabámos de mencionar, podem de um ponto de vista tecnológico ser consideradas núcleos lamelares. Apenas um buril (de ângulo sobre fractura) em sílex Cenomaniano foi

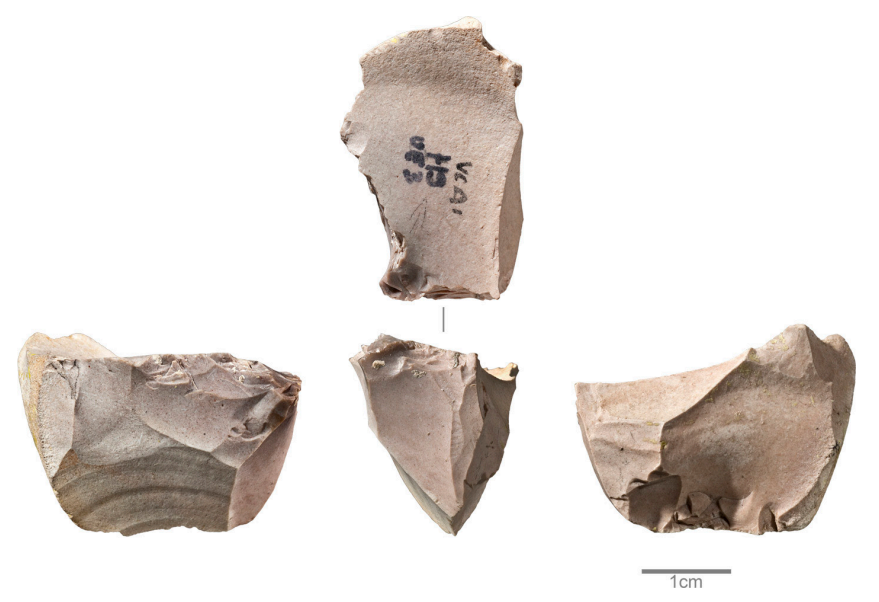

Fig. 13 - Núcleo lamelar em sílex local do limite entre Bajociano e Batoniano (C1) com vestígios de apoio sobre bigorna (UE 3). Foto J. P. Ruas.

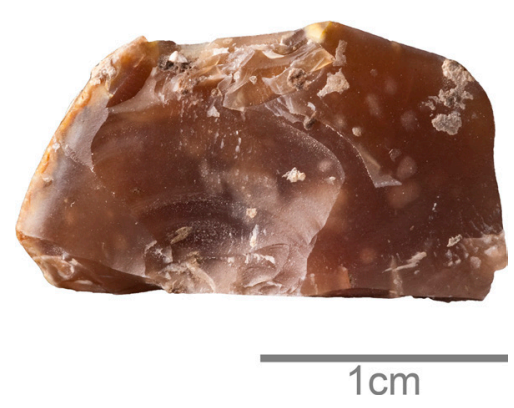

Fig. 14 - Fragmento de núcleo bipolar sobre bigorna provavelmente utilizado para produção de esquírolas em sílex alóctone Cenomaniano (E1/E2) (UE 3). Foto J. P. Ruas.

identificado.

As lamelas retocadas/armaduras representam 29\% (13 peças) do conjunto: sete fragmentos de lamela de dorso, três lamelas de dorso rectilíneo, duas lamelas de Areeiro e uma lamela de dorso marginal. A maioria (7) é produzida em sílex Cenomaniano alóctone e apresenta-se fracturada. Há um exemplar inteiro em sílex local e cinco exemplares em quartzo, estas últimas ligeiramente mais largas do que as restantes. A maioria apresenta uma largura entre 3 e 4 $\mathrm{mm}$ e uma espessura entre 1 e $2 \mathrm{~mm}$. Algumas peças de maiores dimensões podem ter sido regularizadas pelo retoque. No que diz respeito ao tipo de suporte, três peças foram produzidas utilizando lamelas de buril. Estas peças podem ser divididas em dois grandes grupos: peças com dorso abrupto rectilíneo (Fig. 16: 1 e 2) e peças de dorso marginal geralmente apontadas ou bi-apontadas (Fig. 16: 7 e 8). A maioria (10 exemplares) pertence ao primeiro grupo. $O$ dorso é preferencialmente instalado sobre o bordo 


\begin{tabular}{|c|c|c|c|c|c|c|c|c|}
\hline \multirow[t]{3}{*}{ No } & \multirow[t]{3}{*}{ Tipo de utensílio } & \multicolumn{7}{|c|}{ Matérias-primas } \\
\hline & & \multicolumn{3}{|c|}{ Sílex } & \multirow[t]{2}{*}{ Quartzo } & \multirow[t]{2}{*}{ Quartzito } & \multirow[t]{2}{*}{ TOTAL CLASSE } & \multirow[t]{2}{*}{$\%$ CLASSE } \\
\hline & & E1/E2 & C1 & D2/D3 & & & & \\
\hline & RASPADEIRAS & & & & & & 6 & 13,33 \\
\hline $1 \mathbf{a}$ & Raspadeira sobre lâmina & 1 & & & & & & \\
\hline $1 \mathrm{~b}$ & Raspadeira sobre lasca & 2 & & & & & & \\
\hline $5 a$ & Raspadeira sobre lasca retocada & 1 & & & & & & \\
\hline 13 & Raspadeira afocinhada & & & & 1 & & & \\
\hline \multirow[t]{2}{*}{15} & Raspadeira nucleiforme & & 1 & & & & & \\
\hline & BURIS & & & & & & 1 & 2,22 \\
\hline \multirow[t]{2}{*}{$30 a$} & Buril de ângulo sobre fractura & 1 & & & & & & \\
\hline & UTENSILAGEM COMUM & & & & & & 5 & 11,11 \\
\hline 74 & Entalhe & & 1 & & 2 & & & \\
\hline 75 & Denticulado & & 1 & & & & & \\
\hline \multirow[t]{2}{*}{76} & Peça esquírolada & & & & 1 & & & \\
\hline & UTENSILAGEM LAMELAR & & & & & & 13 & 28,89 \\
\hline $85 a$ & Lamela de dorso rectilíneo & 2 & 1 & & & & & \\
\hline $85 f$ & Fragmento de lamela de dorso & 3 & & & 4 & & & \\
\hline $90 \mathrm{~b}$ & Lamela de Areeiro & 1 & & & 1 & & & \\
\hline \multirow[t]{2}{*}{$90 \mathrm{c}$} & Lamela de dorso marginal & 1 & & & & & & \\
\hline & DIVERSOS & & & & & & 20 & 44,44 \\
\hline $92 a$ & $\begin{array}{l}\text { Lâmina, lasca ou lamela com retoque irregular, des- } \\
\text { contínuo ou atípico }\end{array}$ & 4 & 4 & 1 & 2 & 1 & & \\
\hline \multirow[t]{3}{*}{$92 b$} & Fragmento de peça retocada & 3 & 5 & & & & & \\
\hline & \multirow[t]{2}{*}{ TOTAL } & 19 & 13 & 1 & \multirow{2}{*}{11} & \multirow{2}{*}{1} & \multirow{2}{*}{45} & \multirow{2}{*}{100,00} \\
\hline & & & 33 & & & & & \\
\hline
\end{tabular}

Fig. 15 - UE3: Tipologia, por matéria-prima e tipo de utensílio, segundo a lista de J. Zilhão (1997).

esquerdo e o abatimento modifica significativamente a largura (total). O retoque é geralmente directo, oblíquo ou abrupto e muito regular, definindo um bordo rectilíneo.

\subsubsection{OS MATERIAIS LIITICOS RECUPERADOS NA UE4}

Tal como verificado na UE3, a indústria lítica foi orientada para a obtenção de lascas e suportes lamelares e as dez lâminas identificadas (cinco suportes brutos e cinco transformadas em utensílio) não permitem corroborar uma produção laminar autónoma e, provavelmente, correspondem a uma fase inicial da debitagem dos núcleos lamelares. Apenas foram identificados 96 utensílios e destes, 77 são em sílex e os restantes em quartzo (17), quartzo hialino (1) e quartzito (1). Quanto ao tipo de suporte seleccionado para retoque, as lascas constituem a maioria $(50 \%)$, seguidas pelas lamelas $(38,5 \%)$, as lâminas (5\%), as esquírolas (3\%) e os fragmentos ou blocos de matéria-prima (3\%). Foi identificado um entalhe em sílex local, detendo o córtex de alteração típico das plaquetas desta matéria-prima. Os utensílios sobre lasca em sílex Cenomaniano apresentam em média um comprimento inferior a $2 \mathrm{~cm}$. As peças de quartzo $(2,3 \mathrm{~cm})$ e em sílex local $(2,6 \mathrm{~cm})$ apresentam dimensões médias ligeiramente superiores.

A debitagem lamelar focou-se na produção de lamelas pequenas, estreitas e finas com dimensões médias de $160 \mathrm{~mm}$ de comprimento, $4-5 \mathrm{~mm}$ de largura e 1-2mm de espessura (Fig. 21).

A análise morfo-tecnológica detalhada das lamelas brutas (69 lamelas e 11 lamelas de buril) mostra que a maioria das lamelas tem bordos paralelos (16) ou convergentes (14 exemplares), secção triangular (32 exemplares) e um perfil direito (44 exemplares). A orientação dos negativos anteriores ou padrão dorsal é paralela $(43 \%)$ ou convergente $(16 \%)$, mantendo a tendência para o talhe unipolar. $O$ ressalto foi o acidente de talhe mais identificado (8 peças). Em apenas 35 exemplares foi possível observar o talão. Este é punctiforme em 12 

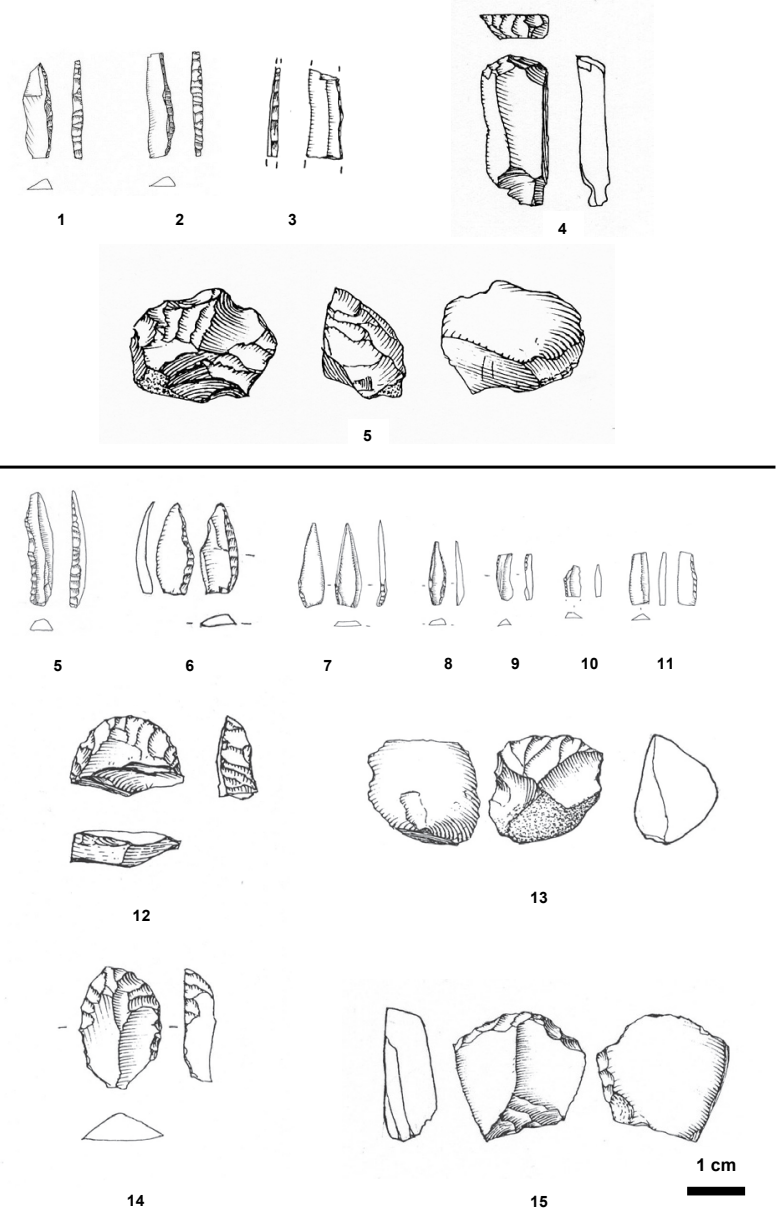

Fig. 16 - Utensilagem em sílex UE3: 1 e 2 - lamelas de dorso rectilíneo ; 3 - fragmento de lamela de dorso ; 4 - raspadeira sobre lâmina ; 5 - raspadeira nucleiforme. Utensilagem em sílex UE4: 5- lamela de dorso rectilíneo; 6 e 7 - lamelas de dorso marginal; 8 - lamelas de Areeiro; 9,10 e 11 - fragmentos de lamelas de dorso; 12, 14 e 15 -raspadeira sobre lasca; 13 - raspadeira nucleiforme (Desenhos T. Aubry).

exemplares, a abrasão foi identificada em 14 peças e o labiado em 16. Mais raramente foi identificado um esquirolamento do bolbo (cinco peças) ou uma linha irregular do talão (uma peça).

Apenas foram recuperados 11 núcleos e cinco fragmentos de núcleo. Os três núcleos exclusivamente para lascas utilizam o sílex local (C1). A debitagem é iniciada a partir de um diedro natural, típico das plaquetas desta matéria-prima, a superfície de debitagem é triangular graças a levantamentos sobre os flancos. Apesar de apresentarem várias superfícies de exploração são sempre unipolares. Como pode ser observado nas Figuras 22 e 24, estes núcleos, apresentam dimensões superiores $(=\mathrm{ou}>5 \mathrm{~cm}$ ) se compararmos com os núcleos em matérias-primas
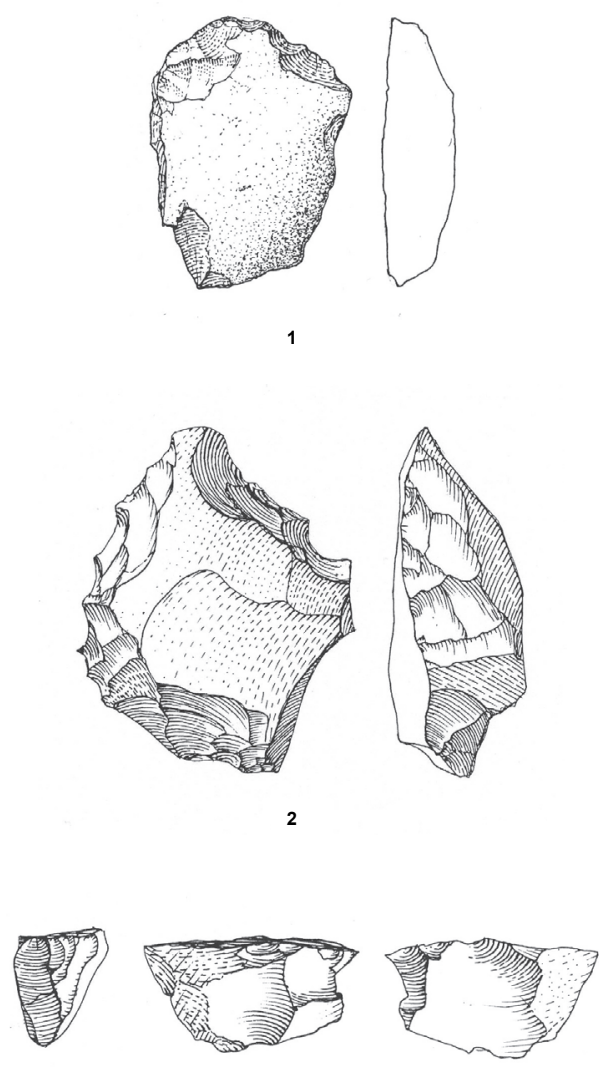

3

$1 \mathrm{~cm}$

Fig. 17 - Utensilagem em quartzo UE4: 1 - raspadeira sobre lasca; 2 -denticulado e 3 - núcleo para lamelas em sílex local (do limite entre Bajociano e Batoniano) (Desenhos T. Aubry).

alóctones, no entanto, a existência de clivagens motiva um rápido abandono (Fig. 22 e 24). Num outro exemplar parece haver insistência do talhador apesar dos ressaltos (provavelmente originados por um ângulo muito aberto) (Fig. 23).

Não podemos descartar a hipótese de algumas lascas em sílex alóctone terem sido produzidas durante as fases iniciais de conformação / preparação dos núcleos lamelares ou que tenham sido introduzidas sob esta forma no Abrigo.

Alguns núcleos em sílex e em quartzo mostram evidências da obtenção de esquírolas ou pequenas lascas através da debitagem sobre bigorna (Fig. 25 e 26). Esta estratégia é utilizada quando as dimensões não permitem outro tipo de exploração. Podemos 


\begin{tabular}{|c|c|c|c|c|c|c|c|c|c|c|c|c|c|c|}
\hline \multirow[t]{4}{*}{ Tipo de núcleo } & \multicolumn{14}{|c|}{ Matéria-prima } \\
\hline & \multicolumn{8}{|c|}{ Sílex } & \multirow{2}{*}{\multicolumn{2}{|c|}{ Quartzo }} & \multirow{2}{*}{\multicolumn{2}{|c|}{$\begin{array}{l}\text { Quartzo } \\
\text { Hialino }\end{array}$}} & \multirow{2}{*}{\multicolumn{2}{|c|}{ TOTAL }} \\
\hline & \multicolumn{2}{|c|}{ E1/E2 } & \multicolumn{2}{|c|}{ C1 } & \multicolumn{2}{|c|}{ C3 } & \multirow{2}{*}{$\begin{array}{l}\text { Ind. } \\
\text { UE3 }\end{array}$} & \multirow{2}{*}{$\begin{array}{c}\text { SI } \\
\text { UE4 }\end{array}$} & & & & & & \\
\hline & UE3 & UE4 & UE3 & UE4 & UE3 & UE4 & & & UE3 & UE4 & UE3 & UE4 & UE3 & UE4 \\
\hline Núcleo para lascas & & & & 3 & & & & & 2 & & 1 & & 3 & 3 \\
\hline Núcleo para lamelas & 1 & 2 & 1 & 2 & 1 & 1 & 1 & & & 1 & & & 4 & 6 \\
\hline Núcleo para pequenas lascas e lamelas & & 2 & 1 & 1 & 1 & & & 1 & 1 & 3 & & & 3 & 7 \\
\hline TOTAL & 1 & 4 & 2 & 6 & 2 & 1 & 1 & 1 & 3 & 4 & 1 & & 10 & 16 \\
\hline
\end{tabular}

Fig. 18 - Tipo de núcleo por matéria-prima nas UE3 e UE4. Tipos de sílex: E1/E2 (Cenomaniano); C1 (limite entre Bajociano e Batoniano local); C3 (limite entre Bajociano e Batoniano alóctone); D2/D3 (Oxfordiano); F2 (silcrete Facho); SI (silcrete indeterminado), Ind. (indeterminado).

\begin{tabular}{|c|c|c|c|c|c|c|c|c|c|c|}
\hline \multirow[t]{3}{*}{ Tipo de volume inicial } & \multicolumn{10}{|c|}{ Progressão da debitagem } \\
\hline & \multicolumn{2}{|c|}{$\begin{array}{c}\text { Bipolar sobre } \\
\text { bigorna }\end{array}$} & \multicolumn{2}{|c|}{ Semi-giratória } & \multicolumn{2}{|c|}{ Frontal } & \multicolumn{2}{|c|}{ Facial } & \multicolumn{2}{|c|}{ Indet. } \\
\hline & UE3 & UE4 & UE3 & UE4 & UE3 & UE4 & UE3 & UE4 & UE3 & UE4 \\
\hline \multicolumn{11}{|l|}{ Núcleos em sílex } \\
\hline Seixo & & & 2 & & & 1 & & & 2 & 1 \\
\hline Bloco & & 1 & & 5 & & 1 & & & & 3 \\
\hline Indeterminado & 1 & & & & & & & & 1 & \\
\hline \multicolumn{11}{|l|}{ Núcleos em quartzo } \\
\hline Seixo & & & & 1 & & 1 & 2 & & & \\
\hline Bloco & & & & & & 1 & & & & \\
\hline Indeterminado & 1 & & 1 & & & & & & & \\
\hline TOTAL & 2 & 1 & 3 & 6 & & 4 & 2 & & 3 & 4 \\
\hline
\end{tabular}

Fig. 19 - Tipo de volume inicial dos núcleos e sua relação com a progressão da debitagem (Valentin, 1995) nas UE3 e UE4.

\begin{tabular}{|c|c|c|c|c|c|c|c|c|c|c|c|c|}
\hline \multirow[t]{4}{*}{ Tipo de volume inicial } & \multicolumn{12}{|c|}{ Hierarquização dos planos de percussão } \\
\hline & \multirow{2}{*}{\multicolumn{2}{|c|}{ Único }} & \multirow{2}{*}{\multicolumn{2}{|c|}{ Bipolar }} & \multirow{2}{*}{\multicolumn{2}{|c|}{$\begin{array}{l}\text { Principal/ } \\
\text { Secundário }\end{array}$}} & \multicolumn{6}{|c|}{ Sucessivos } \\
\hline & & & & & & & \multicolumn{2}{|c|}{ Opostos } & \multicolumn{2}{|c|}{ Cruzados } & \multicolumn{2}{|c|}{ Gémeos } \\
\hline & UE3 & UE4 & UE3 & UE4 & UE3 & UE4 & UE3 & UE4 & UE3 & UE4 & UE3 & UE4 \\
\hline \multicolumn{13}{|l|}{ Núcleos em sílex } \\
\hline Seixo & 2 & 2 & & & 1 & & 1 & & & & & \\
\hline \multicolumn{13}{|l|}{ Bloco } \\
\hline Indeterminado & 1 & 4 & & 1 & & 1 & 1 & 1 & & 1 & & 2 \\
\hline \multicolumn{13}{|l|}{ Núcleos em quartzo } \\
\hline Seixo & & 2 & & & & & 1 & & 1 & & & \\
\hline Bloco & & 1 & & & & & & & & & & \\
\hline Indeterminado & 1 & & & & & & 1 & & & & & \\
\hline TOTAL & 4 & 9 & & 1 & 1 & 1 & 4 & 1 & 1 & 1 & & 2 \\
\hline
\end{tabular}

Fig. 20 - Tipo de volume inicial dos núcleos e hierarquização dos planos de percussão.

supor a utilização de esquírolas em bruto mas a identificação deapenas três esquírolas retocadas (uma raspadeira unguiforme e dois fragmentos de peça retocada) não permite confirmar intencionalidade da debitagem.

A tipologia é maioritariamente composta pela utensilagem lamelar (38,5\%), seguindo-se as (31\%) lascas com retoque irregular, descontínuo ou atípico (incluindo os fragmentos de peças retocadas) com $31 \%$ a que podemos juntar a utensilagem de fundo comum (6\%) que inclui três entalhes e uma peça esquirolada (Fig. 27). As raspadeiras constituem 


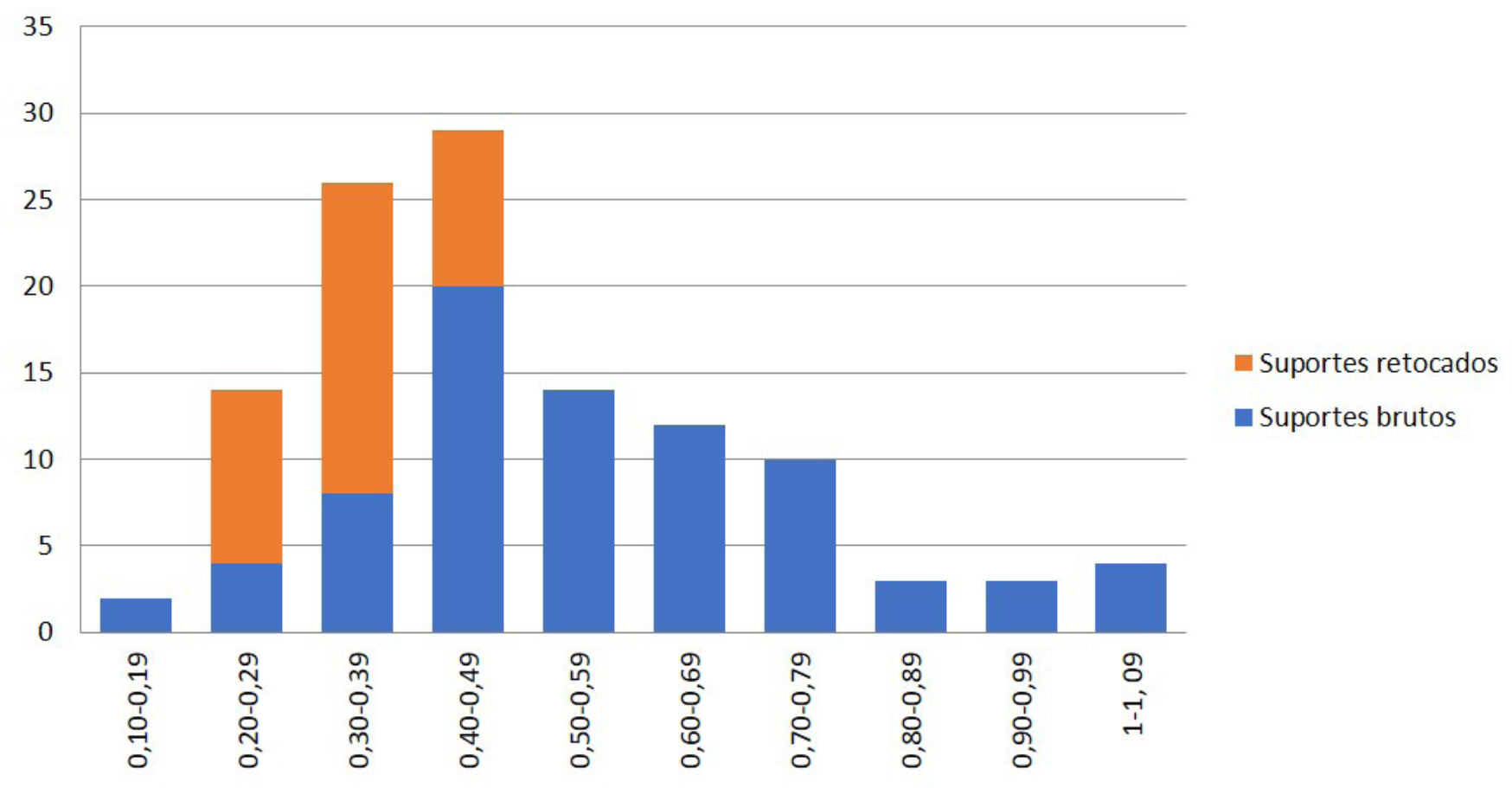

Fig. 21 - Histograma de larguras da totalidade dos suportes alongados da UE4.

$20 \%$ do total da utensilagem retocada e apresentam uma diversidade mais evidente do que no conjunto da UE3. As raspadeiras sobre lasca são o tipo mais numeroso (oito exemplares) mas, no entanto, existem seis exemplares sobre lâmina, de assinalar num contexto com uma percentagem reduzida deste tipo de suporte. Identificámos duas raspadeiras unguiformes, bastante característicos de contextos desta cronologia. A maioria das raspadeiras é de tipo fino, contudo, existem três exemplares de raspadeiras espessas que podem ter sido utilizadas como núcleos: uma raspadeira carenada atípica e duas raspadeiras nucleiformes (Fig. 16:13). A análise traceológica (Aubry - Igreja 2008: 17) permitiu identificar traços de utilização numa das raspadeiras nucleiformes. Outro exemplar classificado como raspadeira nucleiforme não apresentava marcas de uso e a raspadeira carenada atípica apresentava uma superfície de alteração que não permitiu identificar marcas de uso. Os três buris identificados (3\% utensilagem) incluem igualmente um buril nucleiforme que pode ter sido utilizado para debitar lamelas. $\mathrm{O}$ buril diedro direito e o buril sobre truncatura côncava são produzidos sobre suportes pouco espessos e apresentam um bisel com ângulo de $30^{\circ}$, apropriado para utilizar como buril.

As lamelas retocadas/armaduras constituem 38,5\% (37 peças) do conjunto: 16 fragmentos de

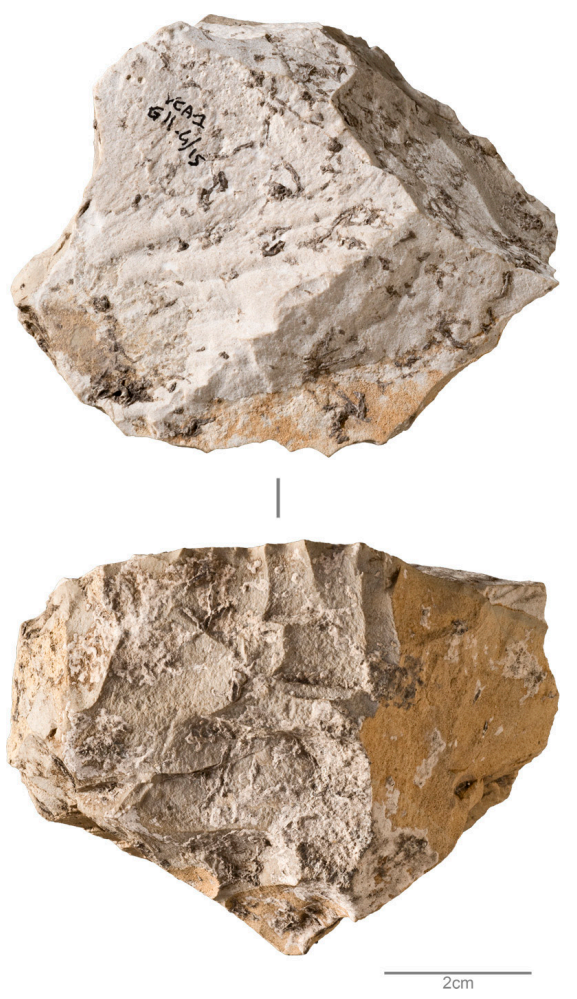

Fig. 22 - Preparação para núcleo lamelar em sílex local do limite entre Bajociano e Batoniano abandonado devido a ressaltos (UE 4). Foto J. P. Ruas.

lamela de dorso, cinco lamelas de dorso duplo, cinco lamelas de Areeiro, três lamelas de dorso marginal e um segmento são as peças mais representativas. 


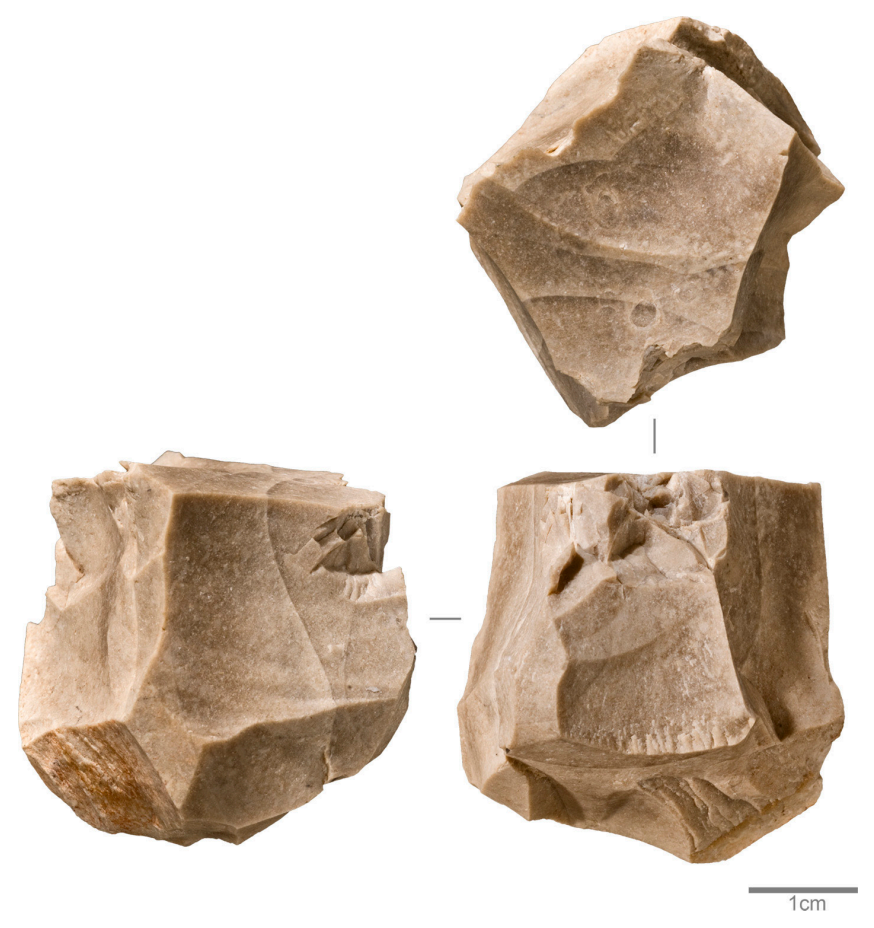

Fig. 23 - Núcleo em sílex local do limite entre Bajociano e Batoniano (C1), para produção de lascas, abandonado devido a ressaltos (UE 4). De salientar a insistência do talhador em continuar apesar dos ressaltos: observe-se os pontos de impacto bem visíveis no plano de percussão. Foto J. P. Ruas.

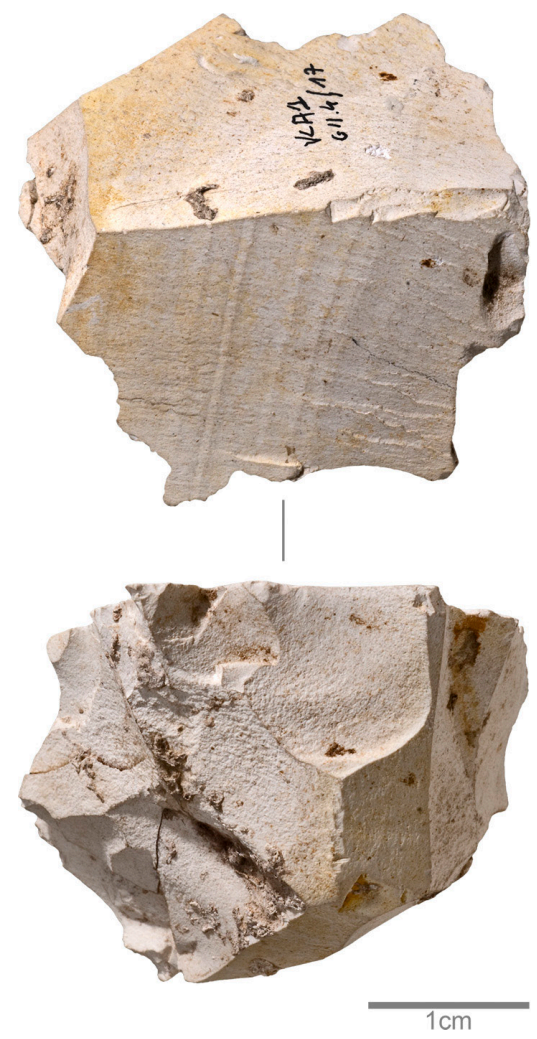

Fig. 24 - Núcleo para lascas em sílex local do limite entre Bajociano e Batoniano (C1) (UE 4). Foto J. P. Ruas.

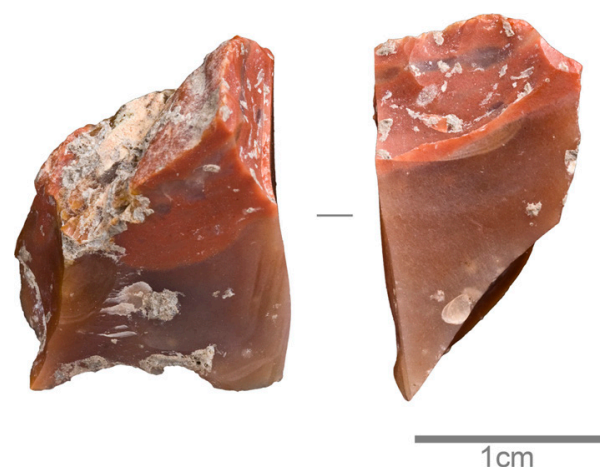

Fig. 25 - Fragmento de núcleo bipolar sobre bigorna, provavelmente para produção de esquírolas, em sílex alóctone Cenomaniano (E1/E2) (UE 4). Foto J. P. Ruas.
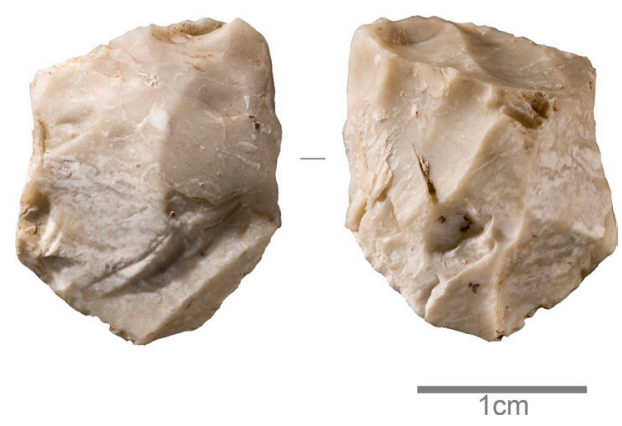

Fig. 26 - Fragmento de núcleo bipolar sobre bigorna, provavelmente para produção de esquírolas, em silcrete indeterminado (UE 4). Foto J. P. Ruas.

De destacar a existência de três truncaturas (uma lamela truncada, uma lamela de dorso truncada e uma lamela de dorso duplo truncada). A maioria (19 peças) é produzida em sílex Cenomaniano alóctone, no entanto apenas quatro exemplares inteiros foram recuperados. De referir a existência de sete peças em quartzo e uma em quartzo hialino. A maioria apresenta uma largura entre 3 e $4 \mathrm{~mm}$ e uma espessura entre 1 e $2 \mathrm{~mm}$. Algumas peças de maiores dimensões podem ter sido regularizadas pelo retoque. No que diz respeito ao tipo de suporte, oito peças foram produzidas utilizando lamelas de buril. As peças seleccionadas para posterior retoque apresentam bordos paralelos (51\%) ou convergentes (22\%), secção triangular (62\%) e perfil direito (78\%) (Fig. 28).

Estas peças podem ser divididas em dois grandes grupos: lamelas de dorso (grupo 85 Zilhão 1997) e lamelas de dorso marginal (grupo 90, Zilhão 1997). No caso do primeiro grupo, há uma preferência para retocar o bordo esquerdo mas os dorsos duplos (ausentes na UE3) constituem 30\% do conjunto. O abatimento do bordo é sobretudo invasor (58\%) e o retoque é maioritariamente directo (87\%) apesar de 


\begin{tabular}{|c|c|c|c|c|c|c|c|c|c|c|}
\hline \multirow[t]{3}{*}{ No } & \multirow[t]{3}{*}{ Tipo de utensílio } & \multicolumn{9}{|c|}{ Matérias-primas } \\
\hline & & \multicolumn{4}{|c|}{ Sílex } & \multirow[t]{2}{*}{ Quartzo } & \multirow{2}{*}{$\begin{array}{l}\text { Quartzo } \\
\text { Hialino }\end{array}$} & \multirow[t]{2}{*}{ Quartzito } & \multirow[t]{2}{*}{ TOTAL CLASSE } & \multirow[t]{2}{*}{$\%$ CLASSE } \\
\hline & & E1/E2 & C1 & D2/D3 & Ind. & & & & & \\
\hline & RASPADEIRAS & & & & & & & & 19 & 19,79 \\
\hline $1 \mathbf{a}$ & Raspadeira sobre lâmina & 2 & & & & & & & & \\
\hline $1 \mathrm{~b}$ & Raspadeira sobre lasca & 1 & 4 & & & 3 & & & & \\
\hline $5 \mathbf{b}$ & Raspadeira sobre lâmina retocada & & 2 & 2 & & & & & & \\
\hline 10 & Raspadeira unguiforme & 1 & 1 & & & & & & & \\
\hline 12 & Raspadeira carenada & 1 & & & & & & & & \\
\hline \multirow[t]{2}{*}{15} & Raspadeira nucleiforme & 2 & & & & & & & & \\
\hline & COMPOSITOS & & & & & & & & 1 & 1,04 \\
\hline \multirow[t]{2}{*}{17} & Raspadeira-buril & 1 & & & & & & & & \\
\hline & BURIS & & & & & & & & 3 & 3,13 \\
\hline 27 & Buril diedro direito & & 1 & & & & & & & \\
\hline 36 & Buril sobre truncatura concâva & 1 & & & & & & & & \\
\hline \multirow[t]{2}{*}{43} & Buril nucleiforme & & 1 & & & & & & & \\
\hline & UTENSILAGEM COMUM & & & & & & & & 6 & 6,25 \\
\hline 74 & Entalhe & & 3 & & & & & & & \\
\hline \multirow[t]{2}{*}{76} & Peça esquírolada & & 1 & & & 2 & & & & \\
\hline & UTENSILAGEM LAMELAR & & & & & & & & 37 & 38,54 \\
\hline 83 & Segmento & & & & & 1 & & & & \\
\hline 84 & Lamela truncada & 1 & & & & & & & & \\
\hline $85 a$ & Lamela de dorso rectilíneo & 1 & 1 & & & & & & & \\
\hline 85d & Lamela de dorso duplo & 4 & & & 1 & & & & & \\
\hline 85 e & Lamela escalena & 1 & & & & & & & & \\
\hline $85 f$ & Fragmento de lamela de dorso & 8 & 2 & 2 & & 4 & & & & \\
\hline $86 a$ & Lamela de dorso truncada & & & & & 1 & & & & \\
\hline 86d & Lamela de dorso duplo truncada & 1 & & & & & & & & \\
\hline $87 a$ & Lamela de dorso denticulado & & & & & 1 & & & & \\
\hline $90 \mathrm{~b}$ & Lamela de Areeiro & 1 & 1 & 2 & & & 1 & & & \\
\hline \multirow[t]{2}{*}{$90 \mathrm{c}$} & Lamela de dorso marginal & 2 & 1 & & & & & & & \\
\hline & DIVERSOS & & & & & & & & 30 & 31,25 \\
\hline 92a & $\begin{array}{l}\text { Lâmina, lasca ou lamela com retoque } \\
\text { irregular, descontínuo ou atípico }\end{array}$ & 1 & 13 & 1 & & & & 1 & & \\
\hline 92b & Fragmento de peça retocada & 4 & 4 & 1 & & 5 & & & & \\
\hline & \multirow[t]{2}{*}{ TOTAL } & 33 & 35 & 6 & 3 & \multirow{2}{*}{17} & \multirow{2}{*}{1} & \multirow{2}{*}{1} & \multirow{2}{*}{96} & \multirow{2}{*}{100} \\
\hline & & & & & & & & & & \\
\hline
\end{tabular}

Fig. 27 - UE4: Tipologia, por matéria-prima e tipo de utensílio, segundo a lista de J. Zilhão (1997).

duas peças apresentarem retoque cruzado e retoque alterno. Quanto à inclinação, o retoque é geralmente abrupto e define um bordo rectilíneo e bastante regular na maioria dos casos. O segundo grupo é menos numeroso (22\%). Frequentemente o retoque afecta os dois bordos e é alterno. A largura do suporte é pouco alterada, portanto o abatimento do bordo retocado é sempre reduzido ou marginal. Quanto à inclinação do retoque esta é sobretudo rasante ou obliqua e delineia bordos convexos e regulares. As fracturas são incaracterísticas e nenhuma pode ser associada a estigmas típicos de impacto.

\section{DISCUSSÃO E CONCLUSÕES}

Como já foi afirmado anteriormente é possível que a UE3 constitua o remeximento do topo da UE4 e apenas por prudência, aguardando resultados da micromorfologia e novas datações radiométricas, os dois conjuntos líticos foram estudados separadamente. A área escavada é igual $\left(9 \mathrm{~m}^{2}\right)$ e no entanto, na UE4, o número de peças é duas vezes 


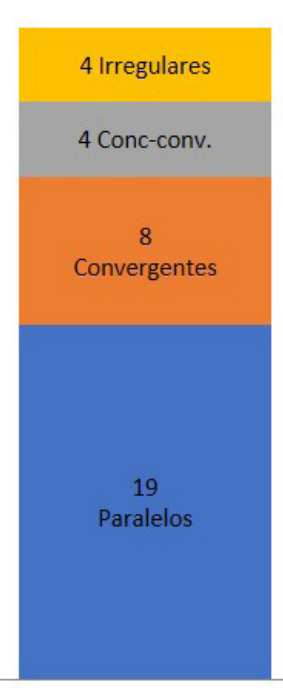

Bordos

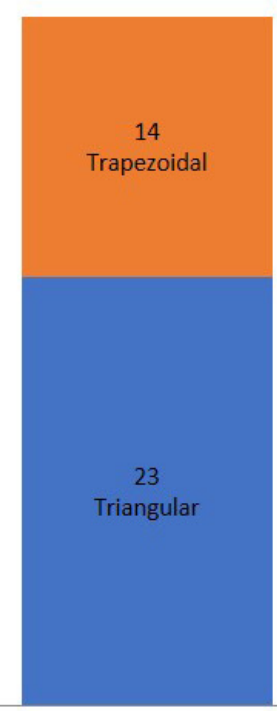

Secção

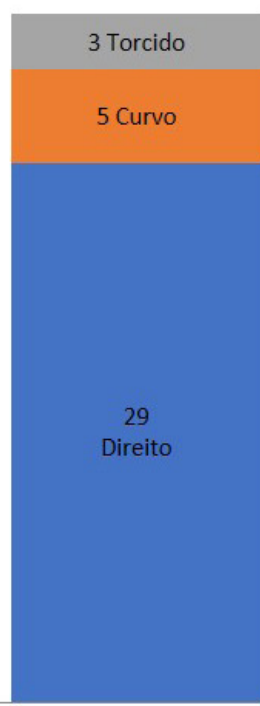

Perfil

Fig. 28 - Morfologia dos bordos, secção e perfil das lamelas retocadas da UE4.

\begin{tabular}{|c|c|c|c|c|c|c|c|}
\hline & \multicolumn{7}{|c|}{ Lateralização do dorso } \\
\hline & \multicolumn{2}{|c|}{ Direito } & \multicolumn{2}{|c|}{ Esquerdo } & \multicolumn{2}{|c|}{ Duplo } & \multirow[t]{2}{*}{ Total } \\
\hline & UE3 & UE4 & UE3 & UE4 & UE3 & UE4 & \\
\hline \multicolumn{8}{|l|}{ Abatimento } \\
\hline Ligeiro* & 1 & & & 3 & 1 & 5 & 10 \\
\hline Marginal & 2 & & 2 & 3 & & 2 & 9 \\
\hline Invasor & 2 & 5 & & 5 & & 4 & 16 \\
\hline Total** & 1 & 2 & 4 & 2 & & 1 & 10 \\
\hline \multicolumn{8}{|l|}{ Orientação } \\
\hline Directo & 5 & 6 & 6 & 12 & 1 & 7 & 37 \\
\hline Indirecto & & & & 1 & & & 1 \\
\hline Alterno & & & & & & 4 & 4 \\
\hline Cruzado & 1 & 1 & & & & 1 & 3 \\
\hline \multicolumn{8}{|l|}{ Inclinação } \\
\hline Abrupto & 2 & 7 & 3 & 6 & & 5 & 23 \\
\hline Oblíquo & 4 & & 3 & 5 & 1 & 4 & 17 \\
\hline Rasante & & & & 2 & & 3 & 5 \\
\hline \multicolumn{8}{|c|}{ Delineação do bordo } \\
\hline Rectilíneo & 6 & 5 & 4 & 11 & & 6 & 32 \\
\hline Convexo & & 2 & 2 & 2 & 1 & 4 & 11 \\
\hline Côncavo & & & & & & 1 & 1 \\
\hline \multicolumn{8}{|l|}{ Regularidade } \\
\hline Irregular & 2 & 1 & 1 & 4 & & & 8 \\
\hline Regular & 1 & 5 & & 8 & 1 & 11 & 26 \\
\hline Muito regular & 3 & 1 & 5 & 1 & & 1 & 11 \\
\hline
\end{tabular}

Fig. 29 - Caracterização do retoque da utensilagem lamelar. *Correspondente ao termo Bordage, em francês; **Quando reduz para metade a largura do suporte original. 
superior. De um ponto de vista da tecnologia lítica não existem diferenças que não sejam explicáveis pela dimensão das duas amostras. Ambos os conjuntos líticos apresentam sensivelmente as mesmas características técnicas, as mesmas fontes de aprovisionamento em matérias-primas e as mesmas percentagens de utilização das mesmas. Foram empreendidos esforços para efectuar remontagens líticas entre as peças das duas unidades estratigráficas, contudo, foi possível associar apenas um fragmento de núcleo da UE3 com o respectivo núcleo recuperado na UE4. Caso se verifique uma diferença cronológica isto poderá significar uma ocupação mais intensa do Abrigo aquando do momento de formação da UE4. Por enquanto, a leitura possível dos diferentes indicadores não possibilita outra interpretação. A exploração das matérias-primas foi efectuada, essencialmente, a nível local. O sílex do limite entre Bajociano e Batoniano (C1), disponível nas proximidades do Abrigo, não apresenta elevada aptidão ao talhe mas foi utilizado para a debitagem de lascas e produção de utensílios do fundo comum, assumindo um papel frequentemente desempenhado pelo quartzito em sítios coevos (Gameiro 2012; Gameiro - Aubry - Almeida 2013). Mesmo se as rochas e minerais disponíveis nas proximidades do Abrigo poderiam ter suprido as necessidades do grupo constatamos o transporte de matérias-primas a distâncias que ultrapassam os $30 \mathrm{~km}$. A exploração, em quantidades reduzidas, de sílex alóctone foi atestada pela presença de sílex do limite entre Bajociano e Batoniano (C3) de melhor qualidade do que o equivalente nas proximidades do Abrigo, que aflora a Norte do Mondego, a cerca de $30 \mathrm{~km}$; de silcrete do Facho (F2) presente na margem esquerda do Rio Mondego, perto da Figueira e de sílex Oxfordiano (D2/D3) disponível no Vale do Nabão a cerca de $50 \mathrm{~km}$ para Sul. Estes dados permitem inferir uma frequentação da zona litoral, a Oeste e a circulação Norte-Sul ao longo do Vale do Nabão, que terá funcionado como um corredor natural de circulação de população humana entre os Maciços de Sicó e os Maciços de Aire e do Vale do Tejo (Gameiro Aubry - Almeida 2008; Aubry et al. 2016).

A debitagem é orientada no sentido da produção de lascas e lamelas e as escassas lâminas identificadas devem corresponder a uma fase inicial de preparação dos núcleos lamelares. Alguns núcleos em sílex e em quartzo evidenciam a obtenção de esquírolas/pequenas lascas a partir da debitagem bipolar sobre bigorna, frequentemente quando as dimensões dos volumes não permitem a utilização de outras estratégias. Esta opção técnica de obtenção de gume cortante com reduzido investimento está igualmente documentada nos sítios do Vale do Côa (Aubry et al. 1998; Aubry 2009; Gameiro 2009). No entanto, em relação ao material do Abrigo 1 de Vale dos Covões, o reduzido número de suportes de reduzidas dimensões apresentando retoque, não permite confirmar a intencionalidade da sua produção apesar de as esquírolas brutas poderem, obviamente, ter sido alvo de utilização. Por outro lado, algumas peças interpretadas como núcleos bipolares podem na verdade constituir o resultado de uma utilização como cunha ou peça intermédia, ou seja, «verdadeiras peças esquiroladas».

Comparativamente aos materiais da UE3, no conjunto recolhido na UE4, a verdadeira diferença reside na identificação de uma verdadeira cadeia operatória de produção de lascas em sílex local (limite entre Bajociano e Batoniano). Regra geral a debitagem tem início a partir do diedro natural, comum nos blocos angulosos ou pequenas plaquetas típicos desta matéria-prima, e a superfície de debitagem é triangular graças a uma conformação básica, debitagem de duas lascas, aplicada sobre os flancos. Estes núcleos podem apresentar múltiplas superfícies de exploração mas a debitagem é sempre unipolar. Fica por confirmar a existência de uma cadeia operatória de produção de lamelas a partir de núcleos sobre lasca, documentada em elevadas percentagens em sítios do Magdalenense Superior da Estremadura (Zilhão 1997; Aubry et al. 1998; Gameiro 2012; Gameiro - Aubry - Almeida 2013). Esta questão coloca-se em relação a um buril e três raspadeiras em sílex Cenomaniano, no entanto, é possível que estas peças tenham conhecido uma utilização dupla enquanto núcleo-utensílio.

A panóplia de utensílios retocados é similar nos dois conjuntos líticos analisados. O facto da utensilagem lamelar ser mais numerosa na UE4 torna mais provável uma maior diversidade formal. A enorme percentagem de peças incluídas da categoria «diversos» tem relação com o estado de conservação e do elevado número de peças fracturadas e queimadas. Comparativamente a outros conjuntos líticos análogos, como a Lapa dos Coelhos, na Estremadura, ou o Fariseu, no vale do Côa, este conjunto apresenta um reduzido número de utensílios do fundo comum (Almeida et al. 2004; Bicho 2000; Gameiro 2012; Gameiro Aubry - Almeida 2013; Zilhão 1997). Este facto, ao qual podemos adicionar a proporção elevada de utensilagem lamelar (> 30\%), poderá ter relação com 
a funcionalidade do local. Em relação à UE3, a análise traceológica de três lascas retocadas atípicas em sílex identificou o trabalho de materiais macios de origem animal (pele) numa das lascas e uma raspadeira afocinhada em quartzo revelou traços de raspagem sobre material orgânico macio (provavelmente pele). Uma raspadeira nucleiforme, proveniente da UE4, possui com traços de raspagem sobre matéria animal dura (haste ou osso). Apenas um fragmento proximal de lamela em sílex Cenomaniano, recuperada na UE3, relevou uma fractura relacionável com estigma de impacto (Aubry - Igreja 2008:17). Os dois principais tipos de lamelas (rectilíneas e apontadas) são coerentes com a diversidade morfológica documentada para este período e podem significar uma montagem compósita associando estes dois tipos na mesma arma de caça. $\mathrm{O}$ número de peças fracturadas em sílex alóctone (por exemplo, 15 das 19 lamelas retocadas em sílex Cenomaniano da UE4 estão fracturadas), pode testemunhar um episódio de reparação de armas de caça no local. Por outro lado, as características do sítio (um abrigo de pequenas dimensões) e o evidente fraccionamento da cadeia operatória, atestado pela ausência de remontagens e a baixa percentagem de utensílios de feição residencial autorizam uma interpretação funcional: provavelmente testemunhamos ocupações curtas e frequentes por pequenos grupos humanos distintos e não perante um sítio utilizado em longa duração, permitindo antever uma utilização relacionada com actividades de âmbito cinegético. A fauna encontra-se em fase de estudo e permitirá dados sobre a evolução conjunta das condições ambientais, escolhas cinegéticas e económicas dos grupos humanas ao longo da sequência. Segundo informação de S. Gabriel, encarregue do estudo faunístico, foram identificados coelho, íbex e veado e resta confirmar a proporção de lagomorfos em relação às restantes espécies. Tratar-se-ia de um acampamento temporário especializado? Tem sido advogado que os sítios da fase final do Paleolítico Superior são reveladores de uma menor especialização funcional, facto explicado por uma elevada mobilidade destes grupos humanos (Crombé et al. 2014; Naudinot 2013; Zilhão 1997:173). Recentemente, sobretudo devido ao elevado número de armaduras identificadas, avançámos a hipótese de as ocupações humanas identificadas na Lapa dos Coelhos, datadas do Bölling-Alleröd, testemunharem actividades especializadas relacionadas com actividades de caça e pesca (Gameiro - Davis - Almeida 2017). Em relação às ocupações humanas que originaram os vestígios materiais que aqui apresentamos, parece-nos mais difícil concluir, qual o tipo de posição deste sítio, no circuito económico dos caçadores-recolectores que o habitaram. A utilização expedita de matérias-primas locais, a que junta a presença de matérias-primas provenientes de Sul e de Oeste parecem indiciar uma elevada mobilidade.

O conjunto destes resultados deve ser apreciado tendo em conta a baixa representatividade da área escavada, a amostra lítica reduzida e as dúvidas relativas às datações por radiocarbono. Apesar das limitações referidas, e aguardando os resultados das datações OSL, em termos cronoculturais, podemos atribuir estas ocupações humanas ao Magdalenense Final, tal como foi definido para a região da Estremadura por $\mathrm{J}$. Zilhão (1997). A panóplia de armaduras existente é consentânea com sítios coevos desta região e para esta cronologia. Recentemente, a inclusão de dados recentes, conduziu alguns autores a classificar alguns contextos portugueses, anteriormente incluídos no fácies Carneira (Zilhão 1997) como azilenses (Aubry et al. 2017). Contudo, dada a ausência de pontas de dorso curvo nos contextos em análise, parece-nos mais prudente uma classificação lata atribuível ao Magdalenense Final.

Podemos concluir que, apesar de algumas questões permanecerem em aberto, a descrição aqui apresentada proporciona elementos importantes para a reflexão e para o conhecimento da região e mais genericamente, contribuí para o conhecimento das dinâmicas de povoamento e dos modos de produção da utensilagem lítica, oferecendo dados para melhorar a nossa imagem das sociedades de caçadores recolectores da Estremadura no final do Paleolítico Superior.

\section{AGRADECIMENTOS}

A autora agradece aos dois revisores anónimos as correcções e sugestões que ajudaram a melhorar este trabalho, a Armando Lucena a realização da base cartográfica do mapa da Fig. 7, a Miguel Almeida a autoria do desenho da planta e corte da sondagem apresentada na Fig. 3, a José Paulo Ruas a realização de todas as fotos de materiais arqueológicos, a Sónia Gabriel e a Luca Dimuccio a transmissão de informação inédita e a Thierry Aubry a realização dos desenhos, algumas fotos e a cedência destes materiais assim como a troca de ideias durante o estudo dos mesmos. 


\section{REFERÊNCIAS BIBLIOGRÁFICAS}

ALMEIDA, F. - ANGELUCCI, D. - GAMEIRO, C. - CORREIA, J. - PEREIRA, T. (2004) - Novos dados para o Paleolítico Superior final da Estremadura Portuguesa: resultados preliminares dos trabalhos arqueológicos de 19972003 na Lapa dos Coelhos (Casais Martanes, Torres Novas). Promontoria 2: 2:157-192.

ANDRADE, M. - MATIAS, H. - GARCIA, M. (2010-2011) - Under Pressure. Remontagens de pedra lascana no contexto de intervenções de emergência: o exemplo dos sítios do Tardiglaciar na área de Leiria. Arqueologia \& História 62-63: 39-50.

AUBRY, T. (ed.) (2009) - 200 séculos da História do Vale do Côa: incursões na vida quotidiana dos caçadoresartistas do Paleolítico (Trabalhos de Arqueologia 52). Lisboa.

AUBRY, T. - ALMEIDA, M. - DIMUCCIO, L. - GAMEIRO, C. - NEVES, M. - KLARIC, L. (2008) - Caracterisation et discontinuites des registes pedosidementaires de l'Occident peninsulaire entre 30000 et 10000 BP: implications sur l'interpretation archéologique. In AUBRY, T. - ALMEIDA, F. - ARAÚJO, A. C. - TIFFAGOM, M. (eds.) - Espace et temps: Quelles diachronies, quelles synchronies, quelles échelles? Procedings of the UISPP meeting (4-9Setembro, Lisboa, 2006) (BARInternational Series 1831). Oxford: 9-21.

AUBRY, T. - BRUGAL, J. - CHAUVIERE, F. - FIGUEIRAL, I. - MOURA, I.- PLISSON, H. (2001) - Modalités d'occupations au Paléolithique supérieur dans la grotte de Buraca Escura (Redinha, Pombal, Portugal). Revista Portuguesa de Arqueologia 4 - 2: 19-46.

AUBRY, T. - DIMUCCIO, L. - ALMEIDA, M. - NEVES, M. - ANGELUCCI, D. - CUNHA, L. (2010) Palaeoenvironmental forcing during the MiddleUpper Palaeolithic transition in central-wertern Portugal. Quaternary Research. Doi: 101016/j. yqres.2010.11.002.

AUBRY, T. - DIMUCCIO, L. A. - MOURA, H. (2017) Paleoambientes e culturas do Paleolítico Superior no Centro e Norte de Portugal: Balanço e perspectivas de investigação. Estudos do Quaternário 17: 29-43.

AUBRY, T. - FONTUGNE, M. - MOURA, H. (1997) - Les occupacions de la grotte de Buraca Grande depuis le Paléolithique Supérieur et les apports de la séquence Holocène à l'étude de la transition Mésolithique/ Néolithique au Portugal. Bulletin de la Societé Préhistorique Française 94-2: 182-190.

AUBRY, T. - GAMEIRO, C. - MANGADO LLACH; J. - LUÍS, L. - MATIAS, H. - PEREIRO, T. (2016) - Upper Palaeolithic lithic raw material sourcing in Central and Northern Portugal as an aid to reconstructing hunter-gatherer societies. Journal of Lithic Studies 3-2. Doi: 10.2218/jls. v3i2.1436

AUBRY, T. - GAMEIRO, C. - SANTOS, A. - LUÍS, L. (2017) - Existe azilense em portugal? Novos dados sobre o Tardiglaciar e o Pré -Boreal no Vale do Côa. In ARNAUD, A. - MARTINS, A. (Coord.) - Arqueologia em Portugal 2017- Estado da questão. Lisboa: 403-418.

AUBRY, T. - IGREJA, M. A. (2008) - Economy of lithic raw materials during the Upper Paleolithic of the Côa Valley and the Sicó Massif (Portugal): technological and functional perspectives. In IGREJA, M.-CLEMENTECONTE, I. (eds.) - Workshop «Recent functional studies on non-flint stone tools: Methodological Improvements and archaeological inferences». Lisboa: 1-25.

AUBRY, T. - MOURA, H. (1993) - Nouvelles données sur les occupations paleolithicques de la region de Redinha (Serra de Sicó, Portugal). In Actas da $3^{\circ}$ Reunião do Quaternário Ibérico. Coimbra: 439-449.

AUBRY, T. - ZILHÃO, J. - ALMEIDA, F. (2007) - À propos de la variabilité technique et culturelle de l'entité gravettienne au Portugal: bilan des dernières découvertes et perspectives de recherche. Paleo 19: 53-72.

AUBRY, T. - ZILHÃO, J. - ALMEIDA, F. - FONTUGNE, M. (1998) - Production d'armatures microlithiques pendant le Paléolithique supérieur et le Mésolithique au Portugal. In Actas del II Congresso de Arqueologia Peninsular. Zamora: 259-272.

BICHO, N. (2000) - Technological change in the final Upper Palaeolithic of Rio Maior (ARKEOS 8). Tomar.

BRACCO, J-P. - MOREL, P. (1998) - Outillage en quartz et boucherie au Paléolithique supérieur: quelques observations expérimentales. In BRUGAL, J.-P. MEIGNEN, L. - PATOU-MATHIS, M. (dirs.) - Économie Préhistorique: les comportements de subsistance au Paléolithique. XVIIle Rencontres internationales $d^{\prime}$ Archéologie et d'Histoire d'Antibes. Sophia Antipolis: 387-395.

CHRISTENSEN, M. - VALENTIN, B. (2004) - Armatures de projectiles et outils: de la production à l'abandon. In PIGEOT, N. (dir.) - Les derniers Magdaléniens d'Etiolles: perspectives culturelles et paléohistoriques (I'unité d'habitat Q31). Paris: 107-160.

CROMBÉ, P. - SERGANT, J. - VERBRUGGE, A. - GRAVE, A. - CHERRETTÉ, B. - MIKKELSEN, J. - VEERLE, C. - KOCK, T. - HUISMAN, H. - VAN OS, B. - VAN STRYDONCK, M. - BOUDIN, M. (2014) - A sealed flint knapping site from the Younger Dryas in the Scheldt valley (Belgium): bridging the gap in human occupation at the Pleistocene-Holocene transition in W Europe. Journal of Archaeological Science 50: 420-439. http:// dx.doi.org/10.1016/j.jas.2014.07.021 
CUNHA, L. (1986) - As buracas das Serras Calcárias de Condeixa-Sicó. Cadernos de Geografia 5: 139-150.

GAMEIRO, C. (2012) - La variabilité régionale des industries lithiques de la fin du Paléolithique Supérieur au Portugal. Tese de Doutoramento apresentada à Université de Paris I- Panthéon-Sorbonne. Edição policopiada.

GAMEIRO, C. (2017) - A utilização do percutor em pedra branda na debitagem lamelar durante o Magdalenense na Estremadura portuguesa / Soft hammerstone percussion use in bladelet debitage during the Magdalenian at Portuguese Estremadura. Journal of Lithic Studies 4 - 3. doi:10.2218/jls.v4i2.2532 GAMEIRO, C.- AUBRY, T. - ALMEIDA, F. (2008) L'exploitation des matières premières au Magdalénien Final en Estremadura portugaise: données des sites de Lapa dos Coelhos et de l'Abrigo dos Covões. In AUBRY, T. - ALMEIDA, F. - ARAÚJO, A. C. - TIFFAGOM, M. (eds.) - Espace et temps: Quelles diachronies, quelles synchronies, quelles échelles? Procedings of the UISPP meeting (4-9Setembro, Lisboa, 2006) (BAR International Series 1831). Oxford: 57-67.

GAMEIRO, C. - AUBRY, T. - ALMEIDA, F. (2013) - A variabilidade regional das indústrias líticas do final do Paleolítico Superior em Portugal. In Arqueologia em Portugal - 150 anos. Actas do Congresso da Associação dos Arqueólogos Portugueses. Lisboa: 277-287.

GAMEIRO, C. - DAVIS, S. - ALMEIDA, F. (2017) - A sequência estratigráfica da Lapa dos Coelhos: funcionalidade e subsistência ao longo do pleistocénico superior no sopé na serra de aire
(Portugal). In ARNAUD, A. - MARTINS,A. (Coord.) Arqueologia em Portugal 2017- Estado da questão. Lisboa: 357-374.

GENESTE， J-M. (1992) - «L'approvisionnement en matières premières dans les systèmes de production lithique : la dimension spatiale de la technologie». In MORA, R. - TERRADAS, X. - PARPAL, A. - PLANA, C. (eds.) - Tecnología y cadenas operativas líticas. Barcelona: 1-36.

INIZAN, M.L. - REDURON, M. - ROCHE, H. - TIXIER, J. (1995) - Technologie de la pierre taillée. Meudon.

KLARIC, L. - GUILLERMIN, P. - AUBRY, T. (2010) - Des armatures variées et des modes de productions variables. Gallia Préhistoire 51: 113-154.

NAUDINOT, N. (2013) - La fin du Tardiglaciaire dans le Grand-Ouest de la France. Bulletin de la Société Préhistorique Française 110-2: 233-255.

PELEGRIN, J. (1995) - Technologie lithique: le châtelperronien de Roc-de-Combe (Lot) et de La Côte (Dordogne). Paris.

PIGEOT, N. (1987) - Magdaléniens d'Etiolles. Économie de débitage et organisation sociale. Paris.

TIXIER, J. - INIZAN, M. L. - ROCHE, H. (1980) - Préhistoire de la pierre taillée. 1-Terminologie et technologie. Antibes.

VALENTIN, B. (1995) - Les groupes humains et leurs traditions au tardiglaciaire dans le bassin parisien. Tese de doutoramento apresentada à Université de Paris I, Panthéon-Sorbonne. Edição policopiada.

ZILHÃO, J. (1997) - O Paleolítico Superior da Estremadura Portuguesa. Lisboa. 


\section{OPHIUSSA}

\section{POLÍTICA EDITORIAL}

A Ophiussa - Revista do Centro de Arqueologia da Universidade de Lisboa foi iniciada em 1996, tendo sido editado o volume 0 . A partir do volume 1 (2017) é uma edição impressa e digital da UNIARQ - Centro de Arqueologia da Universidade de Lisboa.

O principal objectivo desta revista é a publicação e divulgação de trabalhos com manifesto interesse, qualidade e rigor científico sobre temas de Pré-História e Arqueologia, sobretudo do território europeu e da bacia do Mediterrâneo.

A Ophiussa - Revista do Centro de Arqueologia da Universidade de Lisboa publicará um volume anual. A partir de 2018, os artigos submetidos serão sujeitos a um processo de avaliação por parte de revisores externos (peer review). O período de submissão de trabalhos decorrerá sempre no primeiro trimestre e a edição ocorrerá no último trimestre de cada ano.

A revista divide-se em duas secções: artigos científicos e recensões bibliográficas. Excepcionalmente poderão ser aceites textos de carácter introdutório, no âmbito de homenagens ou divulgações específicas, que não serão submetidos à avaliação por pares. Isentas desta avaliação estão também as recensões bibliográficas.

Todas as submissões serão avaliadas, em primeira instância, pela Coordenação Editorial, no que respeita ao seu conteúdo formal e à sua adequação face à política editorial e às normas de edição da revista. Os trabalhos que cumprirem estes requisitos serão posteriormente submetidos a um processo de avaliação por pares cega / blind peer review (mínimo de dois revisores). O Conselho Científico, constituído pela direcção da UNIARQ e por investigadores externos, acompanhará o processo de edição.

Esta etapa será concretizada por investigadores externos qualificados, sendo os respectivos pareceres entregues num período não superior a três meses. Os revisores procederão à avaliação de forma objectiva, tendo em vista a qualidade do conteúdo da revista; as suas críticas, sugestões e comentários serão, na medida do possível, construtivos, respeitando as capacidades intelectuais do(s) autor(es). Após a recepção dos pareceres, o(s) autor(es) tem um prazo máximo de um mês para proceder às alterações oportunas e reenviar o trabalho.

A aceitação ou recusa de artigos terá como únicos factores de ponderação a sua originalidade e qualidade científica. $O$ processo de revisão é confidencial, estando assegurado o anonimato dos avaliadores e dos autores dos trabalhos, neste último caso até à data da sua publicação.

Os trabalhos só serão aceites para publicação a partir do momento em que se conclua o processo da revisão por pares. Os textos que não forem aceites serão devolvidos aos seus autores. O conteúdo dos trabalhos é da inteira responsabilidade do(s) autor(es) e não expressa a posição ou opinião do Conselho Científico ou da Coordenação Editorial. A Revista Ophiussa segue as orientações estabelecidas pelo Commitee on Publication Ethics (COPE, Comité de Ética em Publicações): https://publicationethics.org/

O processo editorial decorrerá de forma objectiva, imparcial e anónima. Erros ou problemas detetados após a publicação serão investigados e, se comprovados, haverá lugar à publicação de correções, retratações e/ou respostas. As colaborações submetidas para publicação devem ser inéditas. As propostas de artigo não podem incluir qualquer problema de falsificação ou de plágio. Para efeito de detecção de plágio será utilizada a plataforma URKUNDU .

As ilustrações que não sejam do(s) autor(es) devem indicar a sua procedência. O Conselho Científico e a Coordenação Editorial assumem que os autores solicitaram e receberam autorização para a reprodução dessas ilustrações, e, como tal, rejeitam a responsabilidade do uso não autorizado das ilustrações e das consequências legais por infracção de direitos de propriedade intelectual.

É assumido que todos os Autores fizeram uma contribuição relevante para a pesquisa reportada e concordam com o manuscrito submetido. Os Autores devem declarar de forma clara eventuais conflitos de interesse. As colaborações submetidas que, direta ou indiretamente, tiveram o apoio económico de terceiros, devem claramente declarar essas fontes de financiamento.

Os textos propostos para publicação devem ser inéditos e não deverão ter sido submetidos a qualquer outra revista ou edição electrónica. Aceitam-se trabalhos redigidos em português, inglês, espanhol, italiano e francês.

Esta edição disponibiliza de imediato e gratuitamente a totalidade dos seus conteúdos, em acesso aberto, de forma a promover, globalmente, a circulação e intercâmbio dos resultados da investigação científica e do conhecimento.

A publicação de textos na Ophiussa - Revista do Centro de Arqueologia da Universidade de Lisboa não implica o pagamento de qualquer taxa nem dá direito a qualquer remuneração económica.

Esta publicação dispõe de uma versão impressa, a preto e branco, com uma tiragem limitada, que será distribuída gratuitamente pelas bibliotecas e instituições mais relevantes internacionalmente, e intercambiada com publicações periódicas da mesma especialidade, que serão integradas na Biblioteca da Faculdade de Letras da Universidade de Lisboa. Conta, paralelamente, com uma versão digital, a cores, disponibilizada no endereço www.ophiussa.letras.ulisboa.pt, onde se pode consultar a totalidade da edição.

Para mais informações: ophiussa@letras.ulisboa.pt 


\section{OPHIUSSA}

\section{EDITORIAL POLICY}

Ophiussa - Revista do Centro de Arqueologia da Universidade de Lisboa started in 1996, with the edition of volume 0. From 2017, this journal is a printed and digital edition of UNIARQ - Centro de Arqueologia da Universidade de Lisboa.

The main objective of this journal is the publication and dissemination of papers of interest, quality and scientific rigor concerning Prehistory and Archeology, mostly from Europe and the Mediterranean basin.

Ophiussa - Revista do Centro de Arqueologia da Universidade de Lisboa will publish an annual volume. From 2018, submitted articles will be subject to a peer-review evaluation process. The submission period will always occur in the first quarter of each year and the edition will occur in the last quarter.

The journal is divided into two sections: scientific articles and bibliographic reviews. Exceptionally, texts of an introductory nature may be accepted, in the context of specific tributes or divulgations, which will not be submitted to peer-review evaluation. Exemptions from this evaluation are also the bibliographic reviews.

All submissions will be considered, in the first instance, by the Editorial Board, regarding its formal content and adequacy in face of the editorial policy and the journal's editing standards. Papers that meet these requirements will subsequently be submitted to a blind peerreview process (minimum of two reviewers). The Scientific Council, constituted by the directors of UNIARQ and external researchers, will follow the editing process.

This stage will be carried out by qualified external researchers, and their feedback will be delivered within a period of no more than two months. The reviewers will carry out the evaluation in an objective manner, in view of the quality and content of the journal; their criticisms, suggestions and comments will be, as far as possible, constructive, respecting the intellectual abilities of the author (s). After receiving the feedback, the author(s) has a maximum period of one month to make the necessary changes and resubmit the work.

Acceptance or refusal of articles will have as sole factors of consideration their originality and scientific quality.

The review process is confidential, with the anonymity of the evaluators and authors of the works being ensured, in the latter case up to the date of its publication.

Papers will only be accepted for publication as soon as the peer review process is completed. Texts that are not accepted will be returned to their authors. The content of the works is entirely the responsibility of the author(s) and does not express the position or opinion of the Scientific Council or Editorial Board.

The Journal Ophiussa follows the guidelines established by the Commitee on Publication Ethics (COPE, the Ethics Committee Publications): https://publicationethics.org/

The editorial process will be conducted objectively, impartially and anonymously. Errors or problems detected after publication will be investigated and, if proven, corrections, retractions and / or responses will be published. Contributions submitted for publication must be unpublished. Article submissions can not include any problem of forgery or plagiarism. In order to detect plagiarism, the URKUNDU platform will be used.

Illustrations that are not from the author(s) must indicate their origin. The Scientific Council and Editorial Board assume that the authors have requested and received permission to reproduce these illustrations and, as such, reject the responsibility for the unauthorized use of the illustrations and legal consequences for infringement of intellectual property rights.

It is assumed that all Authors have made a relevant contribution to the reported research and agree with the manuscript submitted. Authors must clearly state any conflicts of interest. Collaborations submitted that directly or indirectly had the financial support of third parties must clearly state these sources of funding.

Texts proposed for publication must be unpublished and should not have been submitted to any other journal or electronic edition. Works written in Portuguese, English, Spanish, Italian and French are accepted.

The publication of texts in Ophiussa - Revista do Centro de Arqueologia da Universidade de Lisboa does not imply the payment of any fee nor does it entitle to any economic remuneration.

This edition immediately and freely provides all of its content, in open access, in order to promote global circulation and exchange of scientific research and knowledge.

This publication has a limited printed edition in black and white, which will be distributed free of charge by the most relevant international libraries and institutions, and exchanged with periodicals of the same specialty, which will be integrated in the Library of Faculdade de Letras of Universidade de Lisboa. It also has a digital version, in color, available at address http://ophiussa.letras.ulisboa.pt, where one can consult the entire edition.

For more information contact: ophiussa@letras.ulisboa.pt 


\section{ÍNDICE}

CRISTINA GAMEIRO - A tecnologia lítica do fim do Tardiglaciar no centro de Portugal: o exemplo do Abrigo 1 de Vale de Covões (Soure)

JUAN ANTONIO CÁMARA SERRANO - FERNANDO MOLINA GONZÁLEZ - CRISTÓBAL PÉREZ BAREAS LILIANA SPANEDDA - Una nueva lectura de las fortificaciones calcolíticas del Cerro de la Virgen (Orce, Granada, España)

THOMAS TEWS - A quadratura do círculo: sobre a questão da escolha de planta na arquitectura doméstica, no exemplo da Pré-História Recente e Proto-História na Estremadura Portuguesa .. 39 ÍRIS DA COSTA DIAS - A ocupação da Serra do Socorro (Mafra, Torres Vedras) durante o Bronze Final: a colecção de Gustavo Marques

FRANCISCO JOSÉ GARCÍA FERNÁNDEZ - FERNANDO AMORES CARREDANO - ROCIOO IZQUIERDO DE MONTES - ANA MARÍA JIMÉNEZ FLORES - Dos enterramientos singulares de la necrópolis de la Cruz del Negro (Carmona, Sevilla)

FRANCISCO B. GOMES - Equipamentos de culto nos santuários da Idade do Ferro do Sul de Portugal: os altares

ANA SOFIA ANTUNES - Fornos / silos aéreos da arquitectura sidérica peninsular: a propósito de uns "fundos de cabana" e de umas estruturas circulares da Azougada

ANTONIO M. SÁEZ ROMERO - Pucheros y fogones. Aproximación a la evolución de la producción de «cerámicas de cocina» púnicas y tardopúnicas en Gadir .....

MARIA JOSÉ DE ALMEIDA - Contributo para a normalização do registo de informação arqueológica a partir do estudo da via Emerita-Olisipo por Ebora

ALEXANDRA NEPOMUCENO - Fragmentos do Oriente em Leite Vasconcelos

DANIEL CARVALHO - A História da Arqueologia no novo milénio: dimensões, métodos e perspectivas para o caso português

RECENSÕES BIBLIOGRÁFICAS (textos de Juan Álvarez García, Francisco B. Gomes e Elisa de Sousa)

JEAN GUILAINE. DOUTOR HONORIS CAUSA PELA UNIVERSIDADE DE LISBOA (textos de Mariana Diniz, Victor S. Gonçalves e Jean Guilaine)

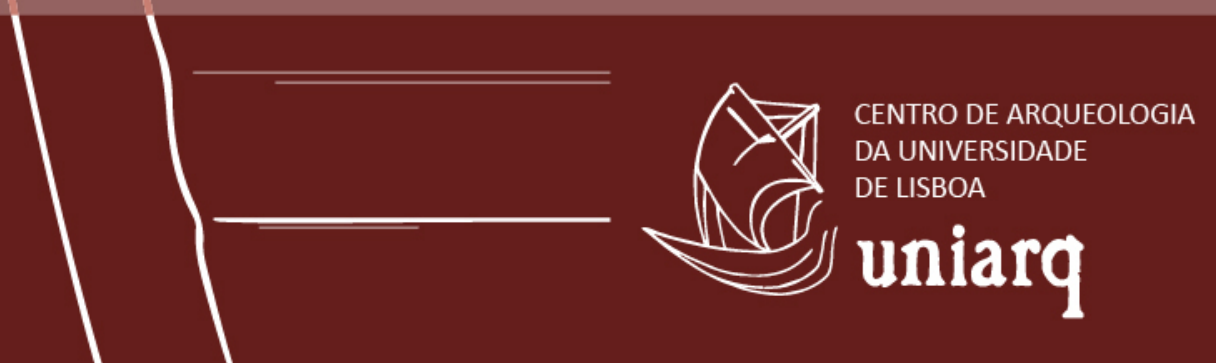

